\title{
Testing the moderating role of trade openness on the environmental Kuznets curve hypothesis: a novel approach
}

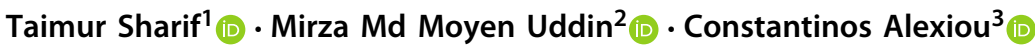

Accepted: 15 December 2021

(c) The Author(s), under exclusive licence to Springer Science+Business Media, LLC, part of Springer Nature 2022

\begin{abstract}
We explore the moderating role of trade openness (TO) by gauging its main and interaction effects on the economic growth and environmental quality nexus. In this direction, we implement a novel approach by using three different measures of pollution emissions $\left(\mathrm{CO}_{2}-\mathrm{CH}_{4}-\mathrm{PM}_{2.5}\right)$ in the environmental Kuznets curve hypothesis and applying a structural equation modelling methodology to 115 countries, grouped into low-, middle- and high-income countries, spanning the period 1992-2018. The evidence suggests that energy consumption has a positive impact on $\mathrm{CO}_{2}$ emissions for all income panels whilst the moderating effect of TO appears to be a key degrading factor of environmental quality in low- and middle-income countries. In addition, TO's interaction with GDP growth is found to negatively affect environmental quality across all income groups. Given that global economies are on the verge of returning to pre-pandemic levels of industrial operations along with emissions in the wake of the failure of COP26 and that COVID-19 has reminded the world the urgency of developing sustainable approaches in fostering 'green economic growth' models; a host of policy measures are proposed in support of this whilst their likely implications are discussed with reference to different income level countries.
\end{abstract}

Keywords $\mathrm{CO}_{2}-\mathrm{CH}_{4}-\mathrm{PM}_{2.5}$ emissions $\cdot$ Moderation effect in EKC $\cdot$ Income level of countries $\cdot$ Trade openness $(\mathrm{TO}) \cdot$ Structural equation modelling (SEM)

Taimur Sharif

t.sharif@newman.ac.uk

Mirza Md Moyen Uddin

mirzamoyen76@gmail.com

Constantinos Alexiou

constantinos.alexiou@cranfield.ac.uk

1 Newman University, Bartley Green, Gunners Lane, Birmingham B32 3NT, UK

2 University of New England, Armidale, Australia

3 Macroeconomics and Policy, Economics and Banking, Cranfield School of Management, Cranfield University, Bedford, UK 


\section{Introduction}

Existing studies on international trade, postulate that trade openness (TO) is one of the driving forces of economic growth (Emerson et al., 2015). Ever since the introduction of the General Agreement on Tariffs and Trade (GATT), global trade has increased exponentially, hence, compelling liberalization of trade amongst countries. Following GATT's reconstitution and emergence as the World Trade Organization (WTO) and its most recent strategic establishment of the Trade Facilitation Agreement (TFA) (WTO, 2017), global trade has experienced a real growth over the years. With a large pool of countries being members of the WTO, economies are emerging as active participants in the global trade through enhanced export-oriented activities and securing a greater financial stake in the international market. Solid trading relationships are enabling countries to boost industrial production and service activities, hence facilitating higher volumes of trade to galvanise economic growth (Zafar et al., 2020). Following its prevalence as a vital instrument in combatting the recent pandemic, trade growth is now projected to emerge as a significant player in fostering the global economic revival (WTO, 2021b). The recently recalculated WTO projection suggests that the global trade volume will see a $10.8 \%$ rise in 2021 , accompanied by market-weighted GDP growth of 5.3\% in the same year, followed by $4.8 \%$ in 2022 (WTO, 2021b).

A large body of the academic literature suggests however that countries prioritizing economic growth based on increasing TO will witness degrading quality of the environment in the form of worsening water quality, deforestation of land, pollution, pandemics and so on due to growing exploitations of natural resources (Emerson et al., 2015; Fang et al., 2018; Wang et al., 2020a, 2020b, 2020c). In this context, accelerated GDP growth is inextricably linked to increased levels of energy usage, emission of pollution into the atmosphere (Chen et al., 2019; Jun et al., 2020) whilst damaging the environment and marring the ecological profile of the country (Kim et al., 2019). Moreover, TO will not only continue to pose environmental threats in the form of higher emissions on the host country but also create a spill-over effect on the bordering countries and long-run externality effects regionally (Gamso, 2018; Halkos \& Polemis, 2018; Sam \& Zhang, 2020). On the global level, the nature of economic interdependence between countries arisen by the acceleration of globalization is thought to pose additional global threats, due in the main, to the relentless exploitation of natural resources and associated pollutions (Adedoyin et al., 2020). The extant empirical findings however reveal inconclusive connectivity between economic growth and environmental pollution (Kassouri \& Altintas, 2020). Also, despite the long-standing debate on the potential environmental ramification of free trade, Emerson et al. (2015) argued that such a relationship is evident, firm and well established whilst Fang et al. (2018) emphasised the need for academics and policymakers to work out possible remedial expedients to this challenge.

In contrast to the above arguments, competing theories of sustainable development (SD) have shown beneficial effects of TO on the environment when different phases of growth are considered (Emerson et al., 2015; Jun et al., 2020), e.g., in the forms of scale-, industrial/structural- and technique/technological- effects (Zhang et al., 2020). In particular, the preponderance of these theories suggests that due to the scale effect of producing more and increasing both consumption of energy and exploitations of natural resources, economic growth generally has a negative environmental effect in its first phase and environmental quality worsens with the rise of trade activities (Rafindadi \& Usman, 2019). As time passes and further economic growth takes place, countries' increasing wealth enables them to create the [industry] composition and/or technology/technique effects and outweigh the scale effect 
on the environment by investing in modernizing the capital stock including green technology, training the workforce, adopting best sustainable management practices, etc. (Emerson et al., 2015; Pothen \& Welsch, 2019) and also responding positively to "increased demand for a cleaner environment, better living conditions, and tightened environmental regulations" (Fang et al., 2018, p.1).

The hypothesized quadratic in nature effect or otherwise known as the nexus between economic growth and environmental defilement is called environmental Kuznets curve (EKC) hypothesis (Abbasi \& Riaz, 2016) which was empirically advanced by some pioneering works, such as Shafik and Bandyopadhyay (1992), Panayotou (1993), Grossman and Krueger (1995), Seldon and Song (1995) and so on. Since then, the EKC hypothesis has been the dominant theory in explaining an inverted U-shaped relationship between environmental depletion and per capita income/GDP or economic growth (Chen et al., 2020; Jalil \& Feridun, 2011; Jalil \& Mahmud, 2009; Kanjilal \& Ghosh, 2013; Mishra, 2020; Rahman, 2020; Shahbaz et al., 2017). This study argues that the existing literature has yet to reach a consensus on the direction of causality among energy consumption, economic growth, and environmental degradation, in which trade is considered to be a vital component of the solution to environmental degradation due to its prospects "to enhance mitigation as well as adaptation efforts" (Brenton \& Chemutai, 2021, p. ix). In light of these backdrops, this paper breaks new ground by exploring the moderating role of trade openness (TO) in the context of the EKC hypothesis, and attempts to fill a gap in literature by gauging its direct and indirect effects in the growth-pollution nexus for 115 WTO-member countries and grouping them into World Bank-classified low-, middle- and high-income panels of countries, spanning the period 1992-2018.

Apart from $\mathrm{CO}_{2}$ emissions, for robustness, this study also considers $\mathrm{CH}_{4}$, and $\mathrm{PM}_{2.5}$ emissions as major sources and proxies for environmental degradation which to the best of the our knowledge has not been attempted before. This research finds that the impact of the moderation effect of TO differs according to the level of income groups and that TO degrades the quality of environment for low- and middle-income countries. The study also observes that the TO 'interaction' with GDP reduce both $\mathrm{CO}_{2}$ and $\mathrm{CH}_{4}$ emissions for high income countries; its 'interaction' with GDP ${ }^{2}$ growth increases both types of emissions, hence implying a Ushaped EKC. In light of these findings, this research broadens the current understanding of the relationship between economic growth and each of these types of emissions. It can be argued that the central focus and findings of this study on the moderating role of 'trade' in the growth-pollution nexus are able to offer useful insights in reforming the global governance and incentive systems in the discourse of fostering and sustaining "green economy" (Mishra, 2020), i.e., also known as circular economy, green growth, low carbon, sustainable growth, etc. (Dubey et al., 2018; Fang et al., 2018; Masi et al., 2018; Song et al., 2019; Yu et al., 2017). Moreover, in the wake of the negative growth experience during COVID-19 and expectations that countries will attempt to bounce back stronger to international trading including aviation and exceed the pre-COVID levels of pollution globally, the authors believe that the evidence produced in this study will be of paramount importance for policy formations or reformations by all stakeholders who strive to materialise the sustainable development (SD) agenda in the above nexus.

The rest of the paper is organized as follows: Sect. 2 provides a brief overview of the pertinent literature whilst Sect. 3 touches upon the empirical strategy implemented in this study. Section 4 presents and discusses the emerging evidence in light of the existing literature whilst Sect. 6 summarizes the findings by providing some policy implications. 


\section{Literature review}

Given that trade is considered to be "a central element of the solution to climate change" and "a critical node to mobilize to achieve green, resilient, and inclusive development in the coming years" (Brenton \& Chemutai, 2021, p. ix), this paper: (a) examines causal relationships between trade openness (TO), economic growth and environmental degradation, and (b) explores the moderating role in main and interaction effects of TO in the context of the EKC. Environmental economists have long debated the validity of this hypothesis and researchers (e.g., Halkos \& Polemis, 2018; He et al., 2017; Jayanthakumaran et al., 2012; Jun et al., 2020) showed a divergent variety of nexus between economic growth/development (e.g., GDP growth, urbanization) and environmental degradation (as a consequence of $\mathrm{CO}_{2}$ emissions, $\mathrm{PM}_{2.5}$ concentration, NOx emissions, wastewater discharge, air quality, industrial soot emissions, etc.) in the EKC hypothesis (Xu et al., 2020). Some of them reinforced the inverted U-curve between the nexus (e.g., Balezentis et al., 2020; Chen et al., 2020; Kanjilal \& Ghosh, 2013; Mishra, 2020; Rahman, 2020; Shahbaz et al., 2017) whilst others challenged its existence in various contexts (e.g., Al-Mulali et al., 2016; Caviglia-Harris et al., 2009; Jaunky, 2011). Another group of researchers observed a repeat of the rise in environmental degradation following its drop to a certain level, suggesting various patterns of the nexus, such as an inverted-V shape (Kijima et al., 2010), an N shape (Halkos \& Polemis, 2018), or a S shape (Pothen \& Welsch, 2019). In light of this backdrop, this study conducts a comprehensive review of the major empirical studies on the economic growth-pollution nexus and sets a logical background for attempting a further investigation of the EKC and checking its variability in various income panels of 115 active member countries of the WTO.

A number of studies produced evidence of the existence of the EKC hypothesis at the global, national or subnational levels. For example, using the ARDL methodology, Jalil and Mahmud (2009) and Jalil and Feridun (2011) observed a quadratic relationship between economic growth and $\mathrm{CO}_{2}$ emissions, and a positive significant impact of $\mathrm{TO}$ on $\mathrm{CO}_{2}$ emissions in China. Kanjilal and Ghosh (2013) studied the long-run association between energy consumption (EC), economic growth, $\mathrm{TO}$ and $\mathrm{CO}_{2}$ emissions for India, and confirmed the existence of the EKC hypothesis where $\mathrm{EC}$ causes $\mathrm{CO}_{2}$ emissions, but $\mathrm{TO}$ has a negative impact on $\mathrm{CO}_{2}$ emissions. Shahbaz et al. (2017) shared similar results for different panel income groups of 105 countries over the period 1980-2014. Overall, their findings confirmed the existence of the EKC hypothesis in most of the income groups of countries and suggested that TO does not affect environmental quality equally when different income levels are considered. In a more recent study, Rahman (2020) used 1971-2013 annual data of the top-10 electricity consuming countries (except Russia), seven of which (i.e., Canada, China, Germany, India, Japan, South Korea, the USA) also belong to the list of top- $10 \mathrm{CO}_{2}$ emitting economies, and confirmed the presence of the EKC phenomenon in the economic growth and $\mathrm{CO}_{2}$ emission nexus. Chen, Xian and $\mathrm{Li}$ (2020) assessed the impact of foreign trade, EC and income inequality on $\mathrm{CO}_{2}$ emissions for G20 countries over the period 1988-2015. The simultaneous quantile regression results suggested that the increase of income and EC propel $\mathrm{CO}_{2}$ emissions whilst TO positively affects $\mathrm{CO}_{2}$ emissions in the short run. In the long run however, TO appears to be reducing $\mathrm{CO}_{2}$ emissions.

On the contrary, there are also a number of studies that do not lend support to the EKC hypothesis. For example, on the global level, Caviglia-Harris et al. (2009) used panel data for 146 countries for the period 1961-2000 and failed to verify the existence of the EKC hypothesis. Al-Mulali et al. (2016) investigated 58 advanced and developing economies for the years 1980-2009 and noticed no sign of the EKC. Abid (2017) applied GMM-system 
method to test the EKC phenomenon across 58 MENA (Middle East \& North Africa) and 41 EU countries for the 1990-2011 time period and observed a monotonically rising nexus between $\mathrm{CO}_{2}$ emissions and GDP (income) in both the countries and also no sign of the EKC presence. The study argued that an inverted-U curve cannot be an automatic outcome, rather a result of the presence of strong environmental policies and strict institutional practices. Likewise, Sarkodie and Strezov (2018) suggested a monotonic shape of the nexus between $\mathrm{CO}_{2}$ emissions and economic growth. Pursuing a different approach, Pothen and Welsch (2019) used the Material Footprint (MF) panel data as an indicator of the materials that are extricated to manufacture the final demand in a country, including imports for 144 countries, and revealed a S-shaped (cubic) and monotonically positive relationship between GDP per capita and MF for most income panels of countries. On the national/country level, InglesiLotz and Bohlmann (2014) and Nasr et al. (2015) used South African data for the 1960-2010 and 1911-2010 time periods respectively, and found no evidence in favour of the EKC hypothesis. Likewise, Nasir et al. (2021) used Australian data for economic growth, TO, $\mathrm{CO}_{2}$ emissions for the period 1980-2014 but found no sign of the EKC phenomenon.

Some scholars obtained mixed results on investigating the validity of the EKC hypothesis. For example, Shafik (1994) examined the relationship between economic growth and pollution (proxied by nine diverse sources of pollution), using a sample of 149 countries over the period 1960-1990. The outcomes of the OLS-based panel data analysis indicated the EKC phenomenon for only sulfur dioxide (SO2) and suspended particles matters (SPM). Later, Aslanidis and Xepapadeas (2006) analysed panel data of 48 states of the USA for the period 1929-1994 using nitrogen oxide (NOx) and SO2 as proxies of emissions. The researchers found no evidence of the EKC for NOx but confirmed the presence of the EKC and a robust smooth inverse-V shaped nexus for SO2. Vehmas et al. (2007) examined the nexus between income and Direct Material Input (DMI), and also income and DMC (DMI excluding exports) in the EU15 for the period 1980-2000. In the first case (DMI), they reported evidence supporting the EKC in case of Germany only. In the second case (DMC), they found the EKCs for the entire EU15 and five countries on the national levels. In a recent study, Shahbaz (2019) employed panel regression and cointegration models to investigate the EKC presence in the Next-11 countries and the empirical findings indicated variable relationships between globalisation and $\mathrm{CO} 2$ emissions in the EKC hypothesis. Table 5 in the appendix provides an effective summary of the key studies in the area.

The above review indicates that the studies that are conducted on investigating the empirical implications of the EKC in the economic growth-pollution nexus witness diverse results due to differences in "samples, pollutants, and methodologies" (Fang, et al., 2018, p.4), and as a result create some degree of ambiguities with varying conclusions and unclear causal linkages in the nexus in question (Busa, 2013; Xu et al., 2020). This backdrop, as also stressed by Amar (2021), justifies the need to revisit of the earlier findings in the EKC literature using contemporary econometric methods, and this is done in this study on a set of more recent panel data of global economies for the period 1992-2018, applying Structural Equation Modelling (SEM) method and also considering two additional proxies of environmental degradation $\left(\mathrm{CH}_{4}\right.$ emissions and $\mathrm{PM}_{2.5}$ emissions), besides the most commonly used proxy (i.e., $\mathrm{CO}_{2}$ emissions) to enhance the validity of the empirical findings. Moreover, in view of the fact that "although much theory and evidence indicate that trade is closely related to income and economic growth, the environmental effect of trade differs systematically from that of economic growth" (Fang, et al., 2018, p.1), this study justifies one of the objectives of conducting an empirical investigation of the role of TO in the economic growth-pollution nexus. 


\section{Empirical investigation}

\subsection{Sample and data}

Given that "a variety of time series, cross-section and panel data analyses indicate that the empirical results are sensitive to the sample of countries chosen and to the time period considered" (Kijima et al., 2010, p. 1188), the study's initial intention was to cover all countries of the world (i.e., 270), as listed in the World Development Indicators (WDI) (2018). However, in alignment with the research aim of investigating the role of TO in the growth-pollution relationship, the list of countries is filtered based on their active WTO memberships and accordingly deduced the target population to be 164 (as of year 2021). The resulting sample size of 115 countries is based on the complete availability of the continuous data for our study variables. Also, to examine the presence of the EKC hypothesis in different income panels of these countries, the official World Bank classifications were followed to segregate the list of countries into 39 high income, 35 upper middle-income, 32 lower middleincome and 9 low-income groups (see Appendix Table 8). Moreover, given that the panel data effectively reflects the dynamics of empirical variables and a large majority of the empirical research on the EKC hypothesis have used country-level panel data to analyse long-run nexus between growth and pollution (Fang et al., 2018; Xu et al., 2020), the same is followed in this study and the period 1992-2018 was covered. Since a number of countries from Central Asian and Baltic regions secured Independence from the former Soviet Union (USSR) and emerged as sovereign countries on the globe during 1988-1991, pre-1992 data were not available for these countries. Therefore, it was logical to consider the 1992-2018 data corresponding to the variables in this study, i.e., $\mathrm{CO}_{2}$ emissions, $\mathrm{CH}_{4}$ emissions, $\mathrm{PM}_{2.5}$ emissions; real GDP per capita, energy consumption (EC), transportation (TR) and trade openness (TO).

\subsection{The variables}

In order to investigate the existence of the EKC hypothesis in the economic growth -pollution nexus in classified income panels of countries and the moderating role of TO in their relationship, environmental degradation is used as the dependent variable, and three different measures of environmental degradation, i.e., carbon dioxide $\left(\mathrm{CO}_{2}\right)$, methane $\left(\mathrm{CH}_{4}\right)$ emissions and concentration of fine particulate matter $\left(\mathrm{PM}_{2.5}\right)$ are considered to ensure robustness. $\mathrm{CO}_{2}$ and $\mathrm{CH}_{4}$ emissions are directly related to global greenhouse effect while $\mathrm{PM}_{2.5}$ causes cardiovascular and respiratory problem and regional climatic change (EPA, 2017, 2021; Forabosco et al., 2017; Wu et al., 2020). Table 6 in appendix provides a summary of the statistics of the variables used in the estimation.

Among all types of pollutants, $\mathrm{CO}_{2}$ is empirically the most influential element in global warming and climate change (Adedoyin et al., 2020; Wang et al., 2020a). The latest estimates suggest that $\mathrm{CO}_{2}$ emissions in the production and marketing of traded goods and services have resulted in a $4-6{ }^{\circ} \mathrm{C}$ increase in the global temperature (Wang et al., 2020a, 2020b, 2020c), in contrast to the COP2 1 target of limiting the warming preferably to $1.5^{\circ} \mathrm{C}$. The G7 countries, BRICS economies, China and its the Belt and Road Countries (BRCs), the Asia Pacific region, and the top-10 electricity consuming countries (except Russia) account $27.3 \%, 37 \%, 50 \%, 50 \%$, and $61.07 \%$ of the global $\mathrm{CO}_{2}$ emissions respectively (Lin et al., 2021; Mahadevan \& Sun, 2020, Rahman, 2020; Wang et al., 2020a, 2020b, 2020c; Zafar et al., 2020). 
$\mathrm{CH}_{4}$ is the second global greenhouse gas (GHG) and it is 80 times more potent than $\mathrm{CO}_{2}$ in acting as a cause of global warming over the next two decades, besides currently causing about 1 million premature deaths annually (UNEP, 2021). Mainly, various anthropogenic activities like agricultural cultivation, rearing livestock, organic and municipal waste landfills are responsible for $\mathrm{CH}_{4}$ emissions (Datta et al., 2012). Although there was about $7 \%$ decline in the $\mathrm{CO}_{2}$ emissions during the COVID-19 lockdowns last year, the volume of $\mathrm{CH}_{4}$ emissions accelerated (NOAA, 2021).

Besides $\mathrm{CH}_{4}$ emissions, other anthropogenic activities like transport exhausts, biomass burning, urbanization, coal-fired manufacturing activities and natural procedure cause $\mathrm{PM}_{2.5}$ emissions (Wu et al., 2020). $\mathrm{PM}_{2.5}$ has significant impact for causing cardiovascular diseases, vascular inflammation, lung cancer, asthma, emphysema, or chronic bronchitis. Children and adults are comparatively more vulnerable to $\mathrm{PM}_{2.5}$ concentration. Sometimes it affects regional climate, lessening visibility and adulterate food and vegetables ( $\mathrm{Li}$ et al., 2016a, 2016b).

The key independent variable is TO, which is perceived to be acting not only as a standalone factor but also as a moderating factor that affects environmental quality. It is evident that countries, especially developing countries, that are reliant on trade have degraded the quality of environment, mostly due to the lack of proper regulations and implementation of existing environmental rules and regulations (Jobert et al., 2016; Yunfeng \& Laike, 2010). Farhani et al. (2013) found $1 \%$ increase in TO increased $\mathrm{CO}_{2}$ emissions by $0.043 \%$ from dirty industries in the MENA region. Researchers (e.g., Gamso, 2018; Halkos \& Polemis, 2018; Sam \& Zhang, 2020) warned that TO can not only damage the environmental quality in the host countries but also has "spillover effects" on the surrounding states. Conversely, Jayanthakumaran et al. (2012) found no effect of TO on environmental degradation in the cases of China and India. Rather, some studies (e.g., Onafowora \& Owoye, 2014; Pothen \& Welsch, 2019; Rafindai \& Usman, 2019) suggested that TO reduces environmental degradation through the enhancement of the capacity of the countries for using advanced technologies in the production process (technology effect). In light of these mixed evidence, the impact of TO appears to be inconclusive, and hence justifies the need for further investigation to revisit its potential contribution to environmental quality (Wang et al., 2020a, 2020b, 2020c). Given that this study also seeks to capture the moderating effect through GDP growth, it makes an interaction of TO with GDP. Also, given the inconclusive results in the extant literature this research makes any a priori assumptions about the hypothesized sign as it can transpire to be either positive or negative.

Economic growth is the most widely used variable in the growth-environmental pollution nexus (e.g., Abdouli \& Hammami, 2016; Rahman, 2020; Umar et al., 2020). Typically, it is measured in real gross domestic product (GDP) or income per capita in most of the studies. Based on the existing evidence, a strong and positive relationship is expected between economic growth and environmental degradation (Jayanthakumaran, et al., 2012). Increasing economic growth enhances not only the integration power and ensure the quality of life but also causes many environmental hazards (Bergasse et al., 2013; Masi et al., 2018). Sustainable path of development hence becomes an imperative prerequisite for the existing and future generations with profound understanding (Song et al., 2019). It should also be noted that the square term of GDP growth will be used to test for potential non-linearities.

Energy consumption (EC), the next explanatory variable here are strong interactions and links between EC and socio-economic development. As a global commodity and cornerstone, EC has a crucial and significant role for most kinds of development (Bergasse et al., 2013). Researchers found divergent results in growth-energy consumption nexus due to time or methodological differences, patterns of energy or economy and heterogeneous climatic 
conditions (Shahbaz, et al., 2013). However, EC has a direct link with economic growth and environmental degradation (Li et al., 2016a). For example, growth of an economy depends on the expansion of economic activities and these involve relentless consumption of nonrenewable energy (e.g., oil, coal, and gas). This leads to convergence into by-products which then contribute into emission of pollution into the atmosphere, resulting in degrading environmental quality in the form of global warming, depletion of ozone layer, etc. (Adedoyin et al., 2020; Wang et al., 2020a). In light of the above backdrop, we expect a significant positive impact of EC on all measures of environmental degradation, i.e., emissions of $\mathrm{CO}_{2}$, $\mathrm{CH}_{4}$, and $\mathrm{PM}_{2.5}$.

Many scholars have exposed the relationship between economic growth and transportation (TR) sector since TR acts as a facilitator to enhance economic growth and economic growth assists reversely to the TR intensity (Lean et al., 2014; Liddle \& Lung, 2013). Also, from the social SD point of view, the transports play a vital role in facilitating a balanced development of the socio-economic systems of a country (Farhadi, 2015). Another aspect of TR is the relationship with GHG emissions as a by-product of fossil fuels. It involves road, railway, aviation and navigation subsectors (EPA, 2021) and as an individual sector it is responsible for $24 \%$ of global emissions (Wang \& Ge, 2019), $29 \%$ of the GHG emissions in the US (EPA, 2021 ) and $25 \%$ of the EU's GHG emissions (EEA, 2020). The transportation-led pollutants such as $\mathrm{PM}_{2.5}, \mathrm{NO}_{2}$, and volatile organic compounds (VOCs) cause cardiovascular and respiratory problems, asthma, bronchitis and allergic rhinitis (EEA, 2020; EPA, 2017; Wu et al., 2020). Moreover, "while most other economic sectors, such as power production and industry, have reduced their emissions since 1990, those from transport have risen" (EEA, 2020 , p.1). It is because of its persistent role as an "essential connector" to all varieties of industrial activities and operations including logistics, supply chain and human mobilities, contributing potentially to as much as $60 \%$ in the global GHGs by 2050 (World Bank, 2020). In light of the above backdrop, this study anticipates a significant positive impact of TR on the alternative measures of emissions considered.

\subsection{Model specification}

In view of the above, economic degradation in the context of the traditional EKC hypothesis is expressed as follows:

$$
E D=f(G D P, E C, T R, T O)
$$

where ED stands for environmental degradation and consists of three measures (i.e., $\mathrm{CO}_{2}$ emissions, $\mathrm{CH}_{4}$ emissions, and $\mathrm{PM}_{2.5}$ emissions); GDP denotes GDP growth; EC stands for energy consumption; TR is transportation; and TO stands for trade openness. $\mathrm{CO}_{2}$ emissions are measured in metric tons per capita, $\mathrm{CH}_{4}$ emissions in kilotons of $\mathrm{CO}_{2}$ equivalent, $\mathrm{PM}_{2.5}$ emissions in microgram per cubic meter; real GDP per capita in constant 2010 US\$, EC in $\mathrm{kg}$ of oil equivalent per capita, TR is measured as percentage of total exports and imports of commercial service and TO is measured as percentage of total trade volume of GDP from the WDI, and adjusted the data for inflation where necessary.

In the recent EKC literature, various econometric methods have been used to investigate the causality between growth and pollution, such as fully modified (Cup-FM) estimates (Chen \& Fang, 2018), the fully modified OLS (FMOLS) (Kasman \& Duman, 2015), generalized method of moments (GMM) (Li et al., 2016a), the spatial panel model (Espoir \& Sunge, 2021), among others. However, in developing an understanding and in order to be able to explain the forms and extent of correlation, variation and covariation among the above set of 
variables (Brommer et al., 2014), a structural equation modelling (SEM) approach is adopted. The methodological review suggests that among 146 relevant publications on SEM applications in ecological studies, SEM was highlighted as a powerful and an increasingly popular technique in scientific investigations for testing various hypotheses with multiple variables having complex webs of causal relationships (Richter et al., 2016). Shah and Goldstein (2006) emphasized SEM as a more appropriate inference framework for most types of causal analyses including mediation. Unlike traditional methods that offer default model, SEM requires development of a priori specification of the forms of directional and non-directional interactions among observed (measured) and unobserved (latent) variables to endorse hypotheses, with research and/or theory (MacCallum \& Austin, 2000). It also investigates "whether the proposed causal relationship is consistent with the patterns [forms] found among variables in the empirical data" (Bollen \& Pearl, 2013, p.12). Moreover, as "quantifying behaviour often involves using variables that contain measurement errors and formulating multi-equations to capture the relationship among a set of variables" (Bollen \& Noble, 2011, p. 15,639), unlike the traditional methods, SEM explicitly indicates error to detect the imperfect nature of the measures. Also, SEM requires multiple measures to explain unobserved variables and hence resolves the occurrence of multicollinearity problems by identifying distinct latent constructs (Stein et al., 2017). In light of these observations, the selection of SEM is deemed to be well justified.

As a platform of conducting the empirical analysis, the effects of regressors on environmental degradation can be expressed in the following equation forms:

$$
\begin{gathered}
C O_{2 i t}=\beta_{0}+\beta_{1}\left(G D P_{i t}\right)+\beta_{2}\left(G D P_{i t}^{2}\right)+\beta_{3}\left(E C_{i t}\right)+\beta_{4}\left(T R_{i t}\right)+\beta_{5}\left(T O_{i t}\right)+\varepsilon_{i t} \\
C H_{4 i t}=\beta_{0}+\beta_{1}\left(G D P_{i t}\right)+\beta_{2}\left(G D P_{i t}^{2}\right)+\beta_{3}\left(E C_{i t}\right)+\beta_{4}\left(T R_{i t}\right)+\beta_{5}\left(T O_{i t}\right)+\varepsilon_{i t} \\
P M_{2.5 i t}=\beta_{0}+\beta_{1}\left(G D P_{i t}\right)+\beta_{2}\left(G D P_{i t}^{2}\right)+\beta_{3}\left(E C_{i t}\right)+\beta_{4}\left(T R_{i t}\right)+\beta_{5}\left(T O_{i t}\right)+\varepsilon_{i t}
\end{gathered}
$$

where $\beta_{0}$ refers to intercepts and $\beta_{1}, \beta_{2}, \beta_{3}, \beta_{4}, \beta_{5}$ indicate coefficients of explanatory variables and $\varepsilon_{i t}$ indicate error terms in Eqs. (2)-(4).

TO is envisaged to have a moderating effect on the relationship between economic growth and environmental degradation. The main purpose of a moderator variable is to modify the form or strength of the relationship between independent and dependent variable in regression analysis. As per literature, two kinds of effects can be measured in moderation effect model: (a) the main effect which is presented in Eqs. (2)-(4), and (b) the moderating effect (Fig. 1) estimates including interaction variables, which is in line with the findings of Chen and Myagmarsuren (2013) and Katircioğlu and Taşpinar (2017). To estimate the main and interaction effects of regressors on the dependent variables of $\mathrm{CO}_{2}, \mathrm{CH}_{4}$ and $\mathrm{PM}_{2.5}$, the variables are normalised and the Eqs. (5)-(7) expressed as follows:

$$
\begin{aligned}
C O_{2 i t}= & \beta_{0}+\beta_{1}\left(G D P_{i t}\right)+\beta_{2}\left(G D P_{i t}^{2}\right)+\beta_{3}\left(E C_{i t}\right)+\beta_{4}\left(T R_{i t}\right) \\
& +\beta_{5}\left(T O_{i t}\right)+\beta_{6}\left[\left(G D P_{i t}\right) \times\left(T O_{i t}\right)\right] \\
& +\beta_{7}\left[\left(G D P_{i t}^{2}\right) \times\left(T O_{i t}\right)\right]+\beta_{8}\left[\left(E C_{i t}\right) \times\left(T O_{i t}\right)\right]+\beta_{9}\left[\left(T R_{i t}\right) \times\left(T O_{i t}\right)\right]+\varepsilon_{i t} \\
C H_{4 i t}= & \beta_{0}+\beta_{1}\left(G D P_{i t}\right)+\beta_{2}\left(G D P_{i t}^{2}\right)+\beta_{3}\left(E C_{i t}\right)+\beta_{4}\left(T R_{i t}\right) \\
& +\beta_{5}\left(T O_{i t}\right)+\beta_{6}\left[\left(G D P_{i t}\right) \times\left(T O_{i t}\right)\right] \\
& +\beta_{7}\left[\left(G D P_{i t}^{2}\right) \times\left(T O_{i t}\right)\right]+\beta_{8}\left[\left(E C_{i t}\right) \times\left(T O_{i t}\right)\right]+\beta_{9}\left[\left(T R_{i t}\right) \times\left(T O_{i t}\right)\right]+\varepsilon_{i t}
\end{aligned}
$$




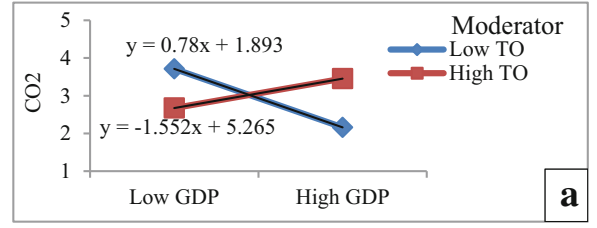

TO dampens the negative relationship between GDP and $\mathrm{CO} 2$

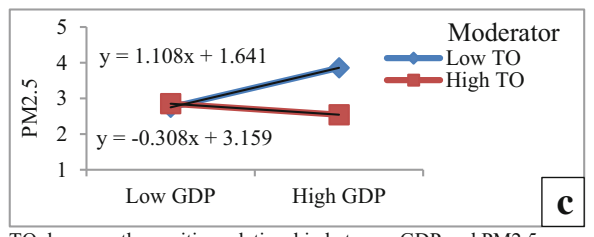

TO dampens the positive relationship between GDP and PM2.5

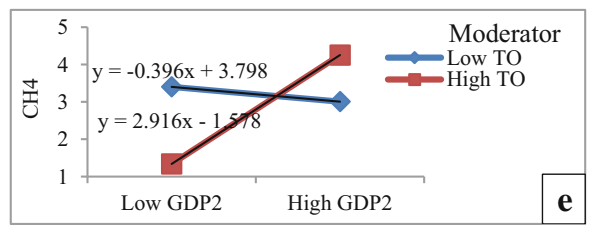

TO strengthens the positive relationship between GDP2 and $\mathrm{CH} 4$

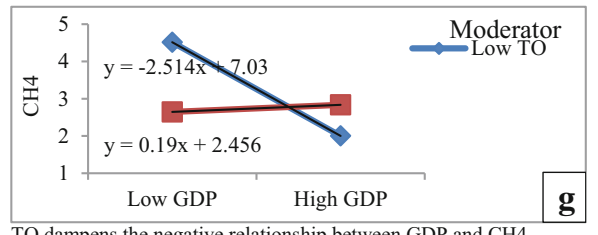

TO dampens the negative relationship between GDP and CH4
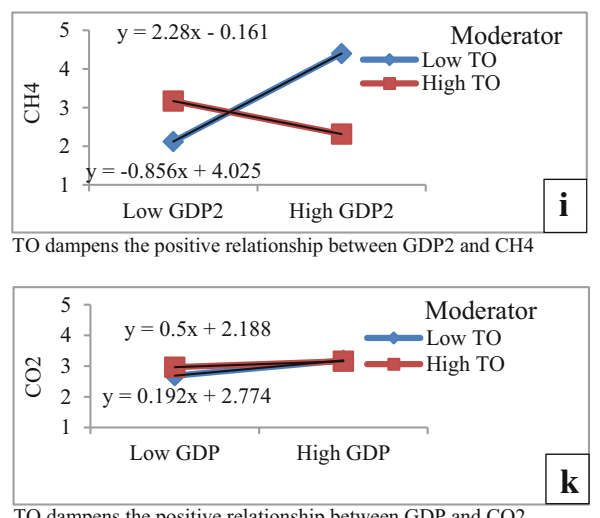

TO dampens the positive relationship between GDP and CO2

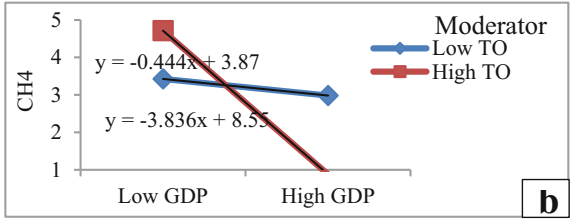

TO strengthens the negative relationship between GDP and CH4

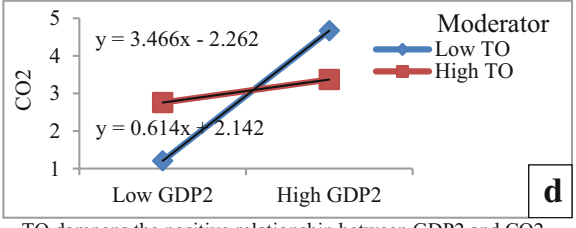

TO dampens the positive relationship between GDP2 and CO2

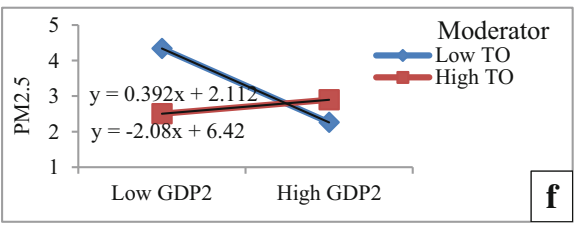

TO dampens the negative relationship between GDP2 and PM2.5
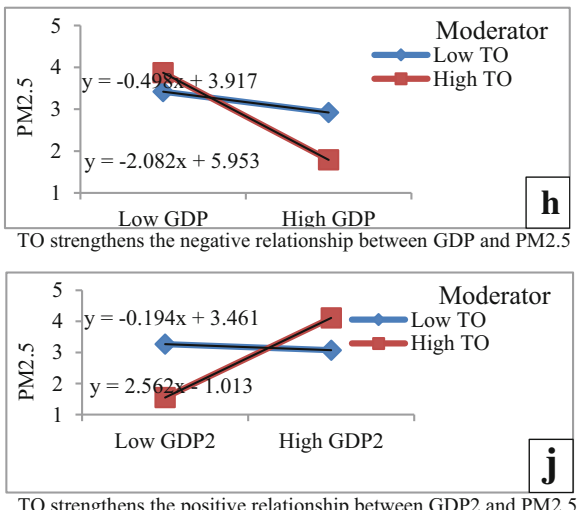

TO strengthens the positive relationship between GDP2 and PM2.5

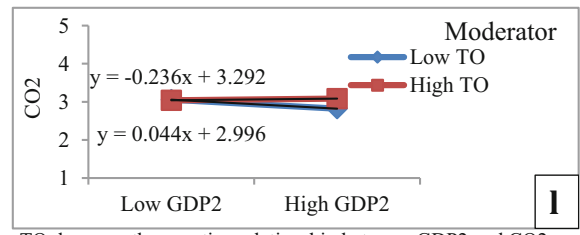

TO dampens the negative relationship between GDP2 and CO2

Fig. 1 a-p Two-way interaction relationship between gross domestic product (GDP \& GDP ${ }^{2}$ ) and selected indicators $\left(\mathrm{CO}_{2}, \mathrm{CH}_{4} \& \mathrm{PM}_{2.5}\right)$ of environmental pollution in different panel income groups 


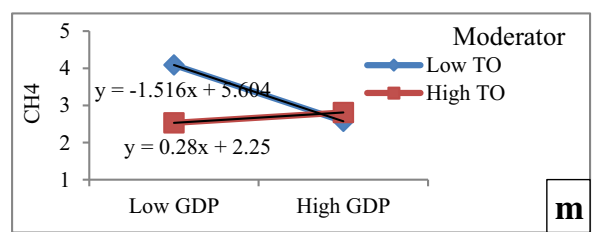

TO dampens the negative relationship between GDP and $\mathrm{CH} 4$

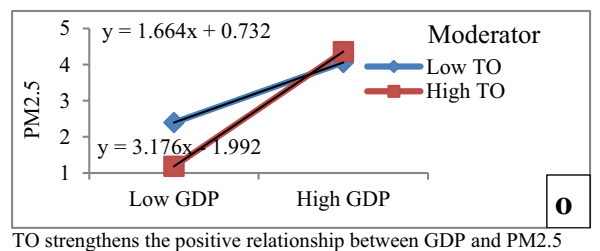

TO strengthens the positive relationship between GDP and PM2.5

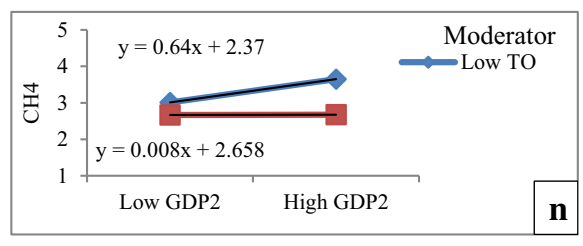

TO dampens the positive relationship between GDP2 and CH4

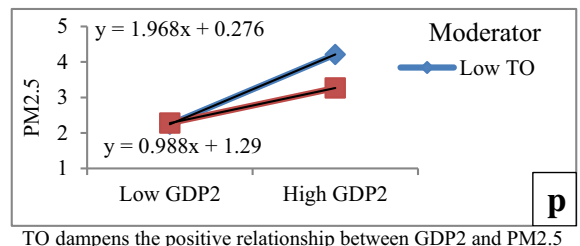

Fig. 1 continued

$$
\begin{aligned}
P M_{2.5 i t}= & \beta_{0}+\beta_{1}\left(G D P_{i t}\right)+\beta_{2}\left(G D P_{i t}^{2}\right)+\beta_{3}\left(E C_{i t}\right)+\beta_{4}\left(T R_{i t}\right) \\
& +\beta_{5}\left(T O_{i t}\right)+\beta_{6}\left[\left(G D P_{i t}\right) \times\left(T O_{i t}\right)\right] \\
& +\beta_{7}\left[\left(G D P_{i t}^{2}\right) \times\left(T O_{i t}\right)\right]+\beta_{8}\left[\left(E C_{i t}\right) \times\left(T O_{i t}\right)\right]+\beta_{9}\left[\left(T R_{i t}\right) \times\left(T O_{i t}\right)\right]+\varepsilon_{i t}
\end{aligned}
$$

The Eqs. (5)-(7) propose that TO exerts influences on the relationship between the independent variables and the dependant variables (i.e., the indicators of environmental degradation). These influences are known as moderating effect in statistical analysis (Cohen et al., 2003). Analysis of Moment Structures (AMOS 25) is used to test the moderation effect in this study.

\section{Results}

\subsection{Validity analysis and CFA}

In order to assess the validity of the measurement model, prior to the empirical assessment, reliability analysis and confirmatory factor analysis (CFA) are conducted using the maximum likelihood estimation technique and items are reconstructed based on the results of CFA. Reliability analysis is a procedure used to estimate the consistency of the measured items and the appropriateness of the model.

The recommended good fit indices are represented in Table 1 which is in line with the findings of Shah and Goldstein (2006) and Hasan et al. (2014). The Chi ${ }^{2}$ test depends directly on the sample size while CFI, GFI, NFI and TLI are of acceptable fit if $>0.95$, poor fit if $>$ 0.90 and SRMR if $<0.06$ (Hu \& Bentler, 1998), RMSEA if $<0.05$ good fit, adequate fit if < 0.08 (Browne \& Cudeck, 1993).

\subsection{Long-run coefficients of the main effect in path analysis}

The value of the coefficients in main and interaction effects differ in classified income groups, particularly in low-income countries where GDP reduces but $\mathrm{GDP}^{2}$ increases $\mathrm{CO}_{2}$ emissions 


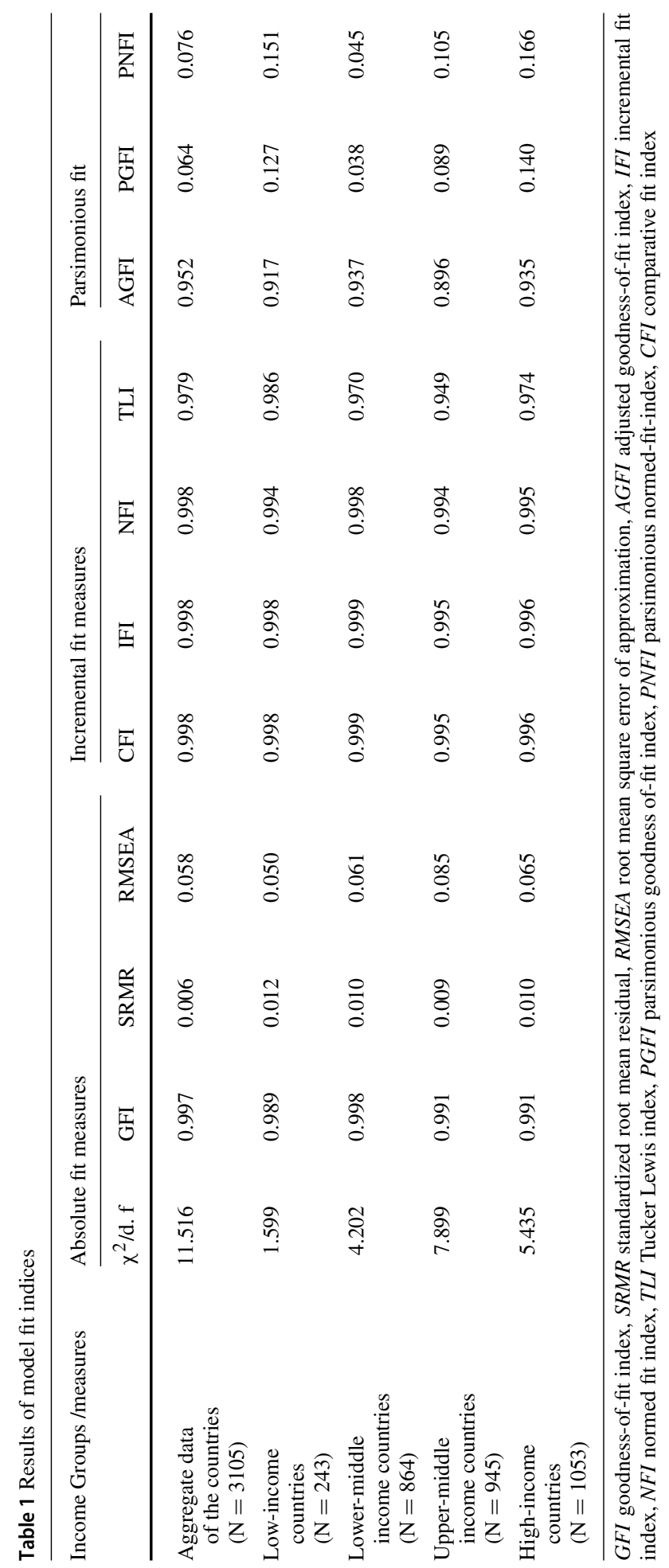




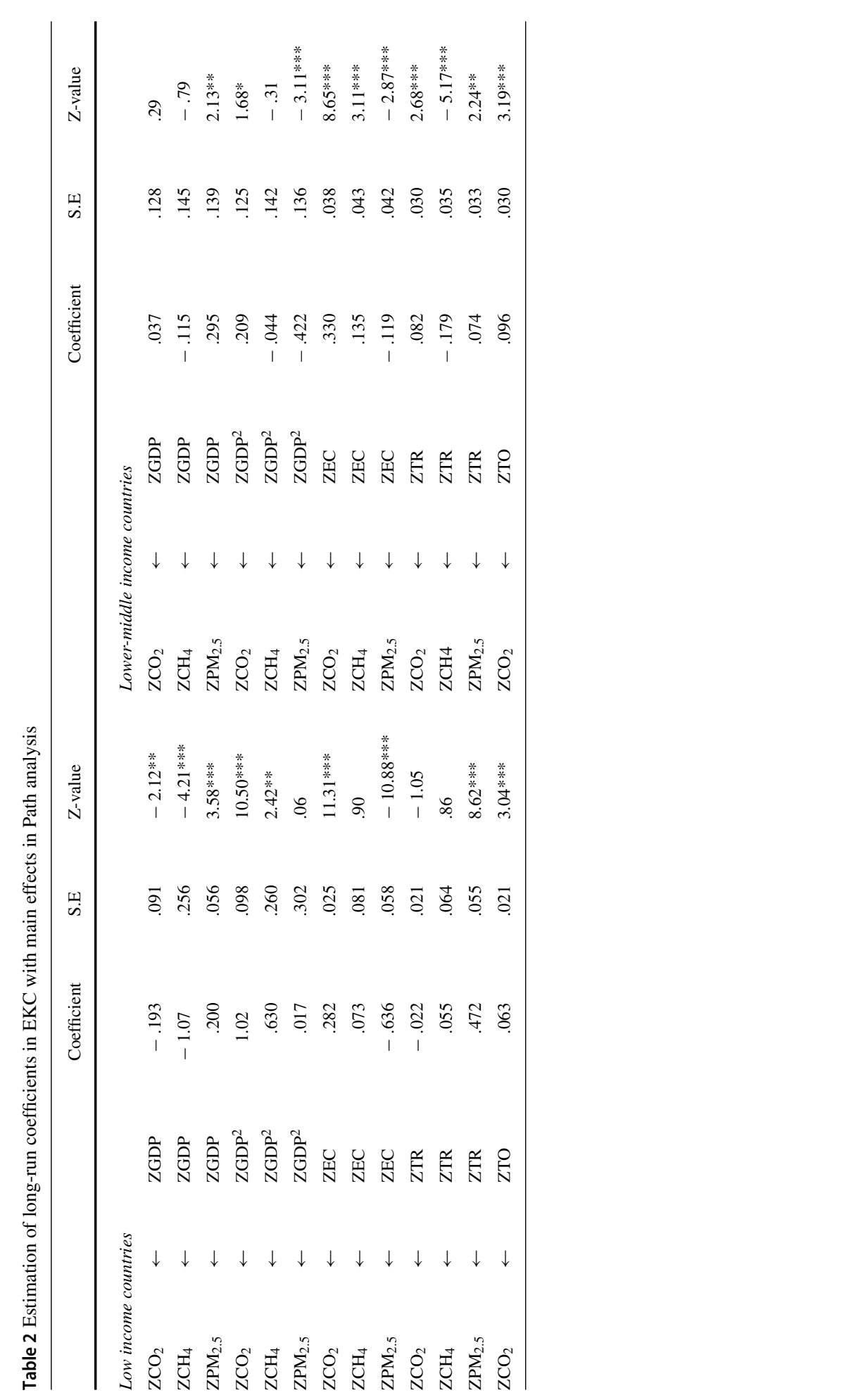




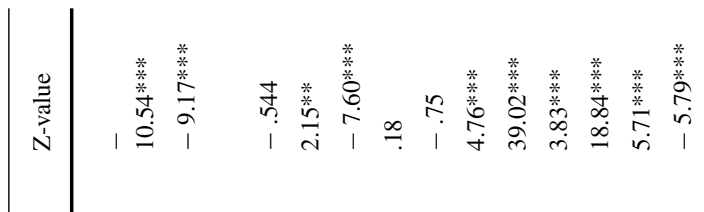

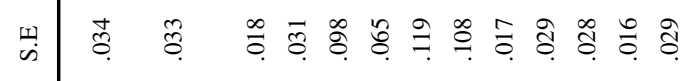

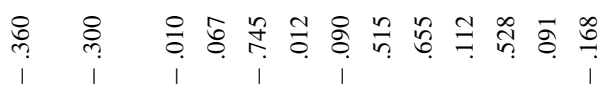

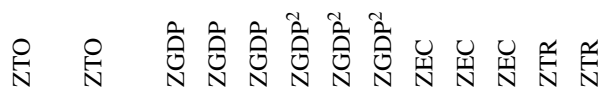

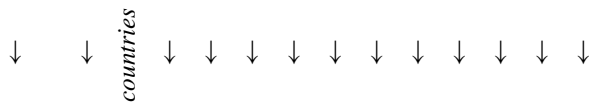

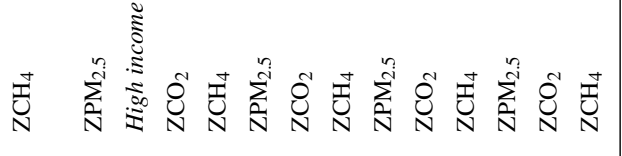

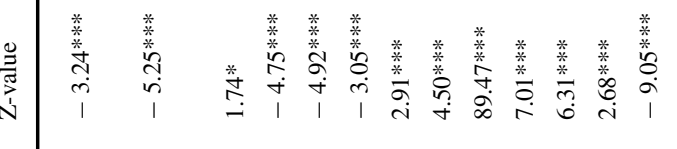

$$
\begin{aligned}
& \text { य } \\
& \text { 焉 } \\
& \text { 兽 }
\end{aligned}
$$

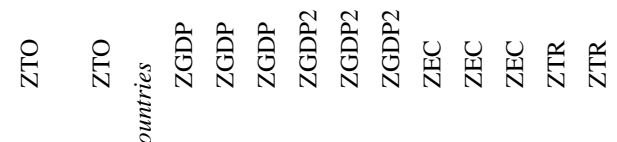

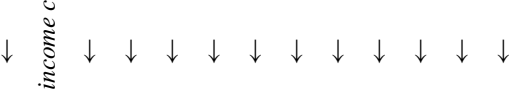

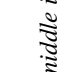

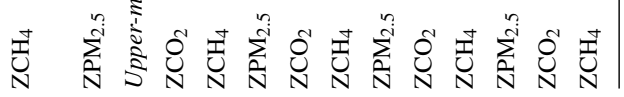




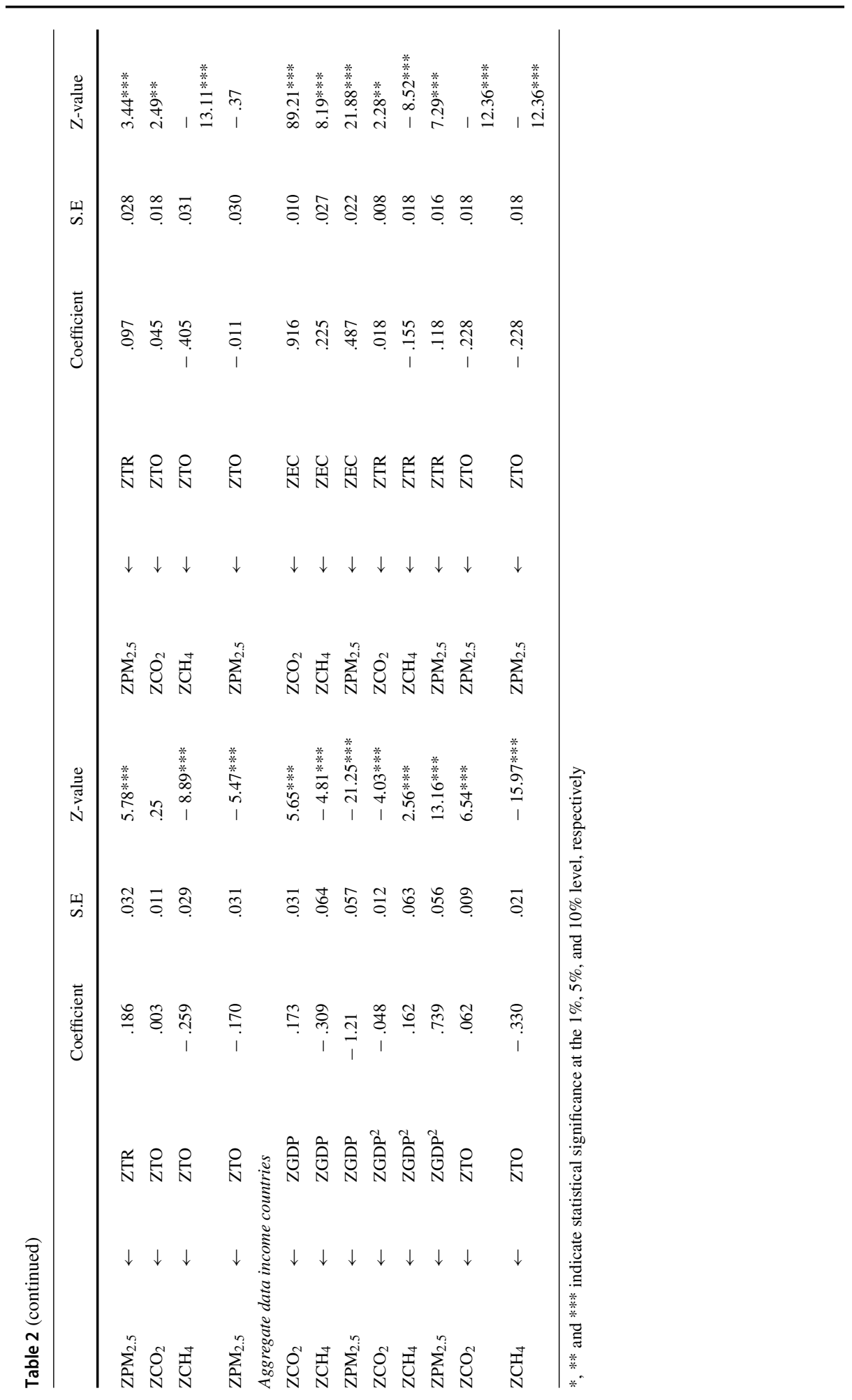




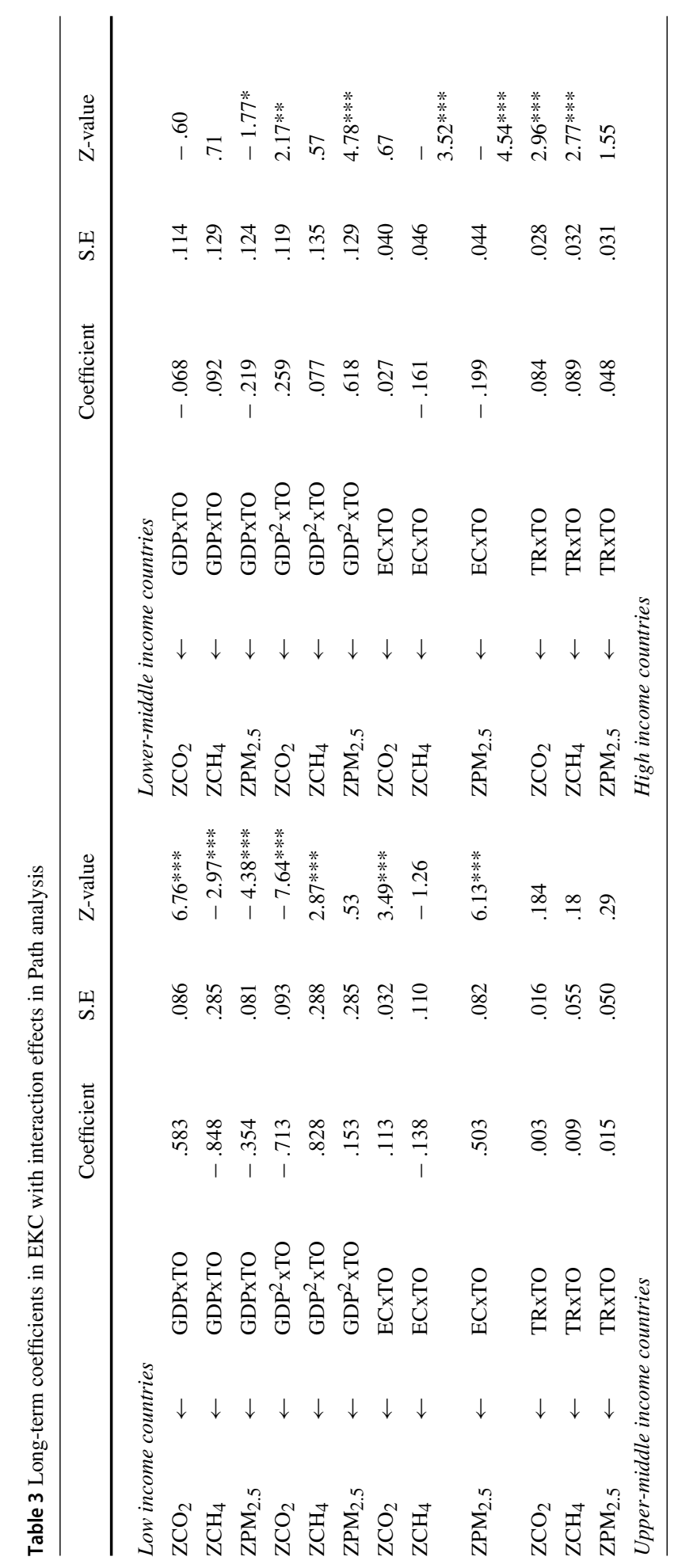




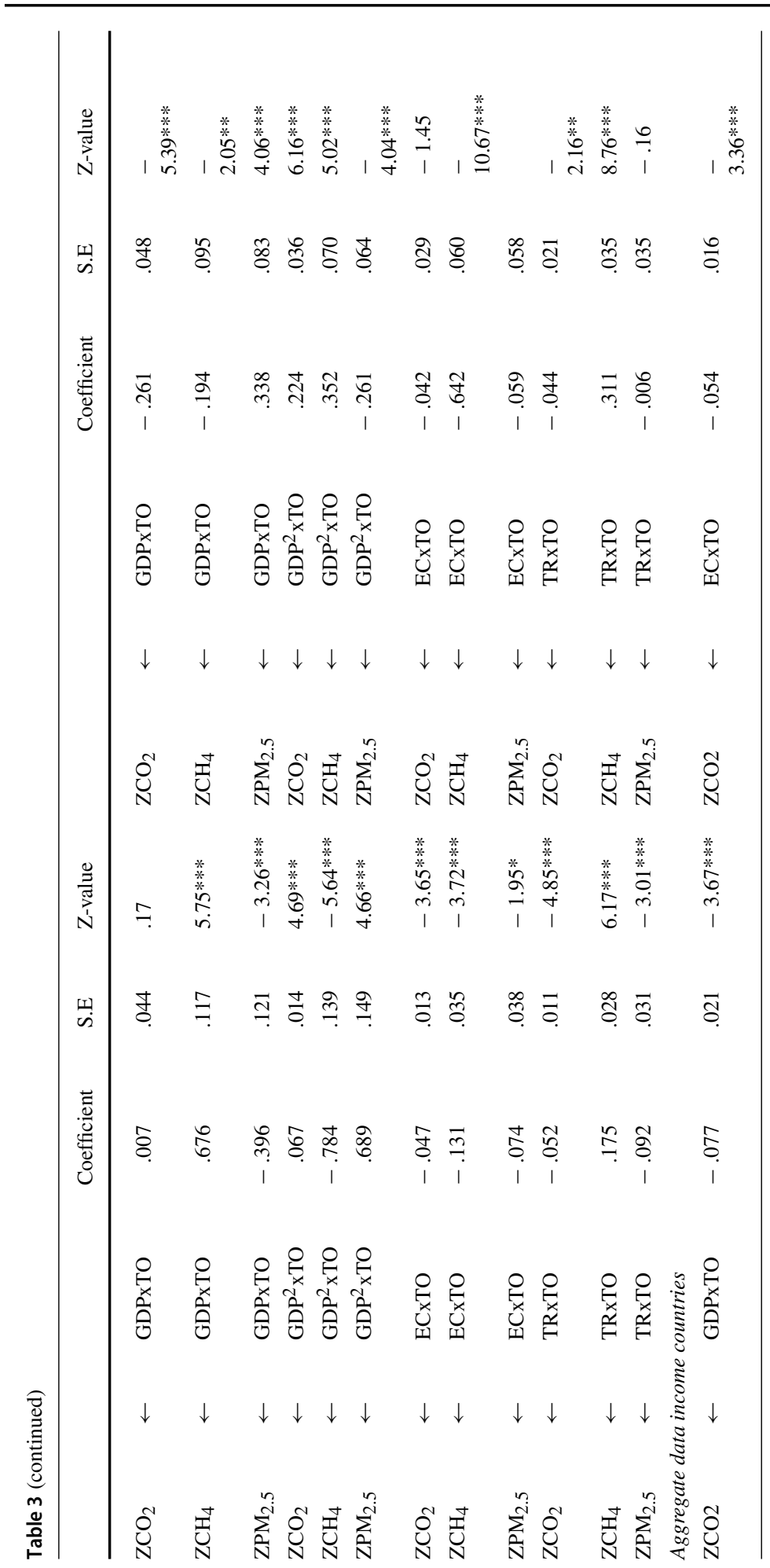




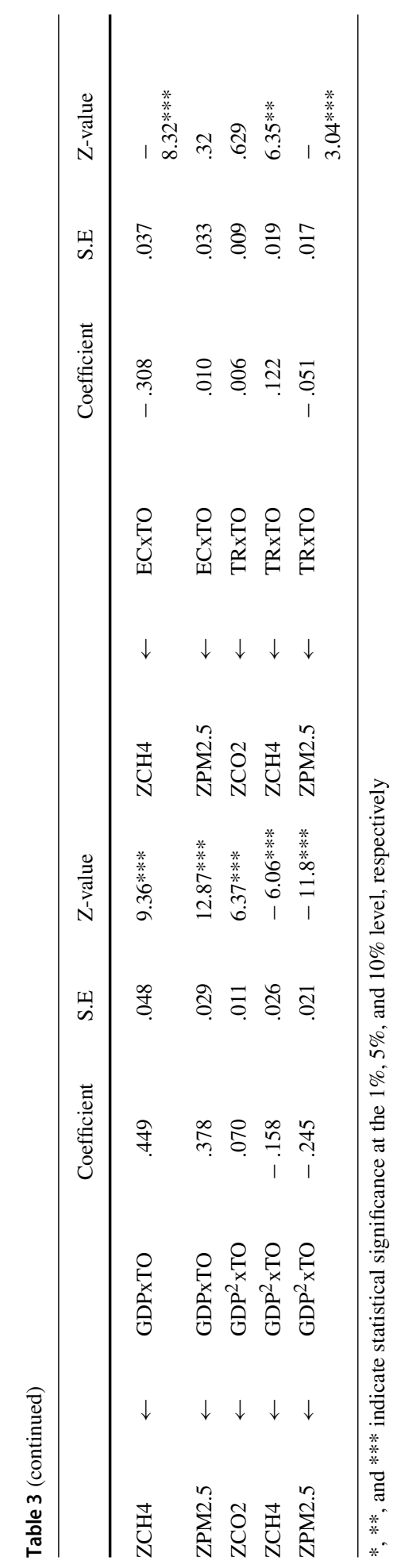


(see Table 2), indicating U-shaped EKC. Again, GDP growth shows positive impact but GDP2 growth reveals the significant negative impact in reducing $\mathrm{CO}_{2}$ emissions in upper-middle-, and aggregated-income groups, supporting the inverted $\mathrm{U}$-shaped $\mathrm{EKC}$. In $\mathrm{CH}_{4}$ emissions, GDP growth shows significant negative impact for low, upper-middle-, and aggregatedincome groups and positive impact on emissions for high income group. However, GDP ${ }^{2}$ has significant positive impact on $\mathrm{CH}_{4}$ for low, upper-middle-, and aggregated-income groups depicting a U-shaped EKC, meaning that further economic growth raises $\mathrm{CH}_{4}$ emissions in these income groups. Furthermore, in $\mathrm{PM}_{2.5}$ emissions, GDP has a significant positive impact for low and lower-middle income groups while it reduces $\mathrm{PM}_{2.5}$ emissions for upper-middle, high income and aggregated income groups. Again, GDP ${ }^{2}$ increases $\mathrm{PM}_{2.5}$ emissions for low, upper-middle, high income and aggregated income groups implying that $\mathrm{PM}_{2.5}$ raises along with further economic growth.

\subsection{Long-run coefficients of interaction effect in path analysis}

The results of interaction effects differ from the main effect significantly. GDP interaction with TO reveals the significant negative impact on $\mathrm{CO}_{2}$ emissions for high income and aggregated income groups while it shows significant positive impact on the emissions for low-income group (see Table 3 ). However, GDP ${ }^{2}$ interaction with TO depicts a significant positive impact on $\mathrm{CO}_{2}$ emissions for all the income groups except low-income group meaning that $\mathrm{TO}$ causes $\mathrm{CO}_{2}$ emissions with further GDP growth.

In $\mathrm{CH}_{4}$ emissions, TO interaction with GDP reveals the significant negative impact for low, and high-income groups while it shows positive impact for upper-middle, and aggregatedincome groups. However, TO interaction with GDP ${ }^{2}$ shows the positive impact for low, and high-income groups depicting U-shaped EKC while TO interaction with $\mathrm{GDP}^{2}$ indicates significant negative impact on $\mathrm{CH}_{4}$ emissions in upper-middle-, and aggregated-income groups depicting an inverted a U-shaped EKC.

Finally, in $\mathrm{PM}_{2.5}$ emissions, TO interaction with GDP shows negative impact for low, lower-middle, and upper-middle income groups while it shows positive impact for high income and aggregated income groups. Moreover, $\mathrm{GDP}^{2}$ interaction with TO leads to positive impact on $\mathrm{PM}_{2.5}$ emissions in lower and upper-middle income groups but it reduces $\mathrm{PM}_{2.5}$ emissions for high income and aggregated income groups portraying EKC hypothesis.

\subsection{Two-way interactions}

The two-way interaction effect demonstrates that the independent variable (IV) as the one whose relationship with the dependent variable (DV) is being moderated whereas the moderator is the other IV doing the moderating effect. The interaction is the product variable and the intercept/constant indicates the vertical position for the graph (see set of Fig. 1a-p). In this study, two-way interaction shows the relationship between IV (i.e., GDP) and each of the DVs is moderated by the other IV (i.e., TO) as the moderator. The two-way interactions highlight some dampening and strengthening relationships in respective to high and low flow of moderator (i.e., TO) in different income panel countries on the EKC. "Dampening" means weakening negative or positive relationship between the two IVs (i.e., GDP and $\mathrm{CO}_{2}$ ) and strengthening means intensifying positive or negative relationships between the variables.

The set of Figures depicts that TO dampens the negative relationship between GDP and $\mathrm{CO}_{2}$ (Fig. 1a) and dampens the positive relationship between $\mathrm{GDP}^{2}$ and $\mathrm{CO}_{2}$ for low-income group (Fig. 1d) in support to the EKC. TO dampens the negative relationship between 
GDP and $\mathrm{CH}_{4}$ emissions for upper-middle income (Fig. 1g) and aggregated income groups (Fig. 1m), meaning that TO interaction with GDP degrades the quality of environment. While the interaction effect of TO dampens the positive relationships between $\mathrm{GDP}^{2}$ and $\mathrm{CH}_{4}$ for upper-middle (Fig. 1i) and aggregated income groups (Fig. 1n), it leads to reduces $\mathrm{CH}_{4}$ emissions in support to the EKC.

In $\mathrm{PM}_{2.5}$ emissions, the interaction effect of TO dampens the positive relationship between GDP growth and $\mathrm{PM}_{2.5}$ emissions for low-income group (Fig. 1c), between GDP ${ }^{2}$ growth and $\mathrm{PM}_{2.5}$ emissions for aggregated income group (Fig. 1p) and strengthens negative relationship between GDP and $\mathrm{PM}_{2.5}$ for upper-middle income group (Fig. 1h). However, TO strengthens the positive relationship between $\mathrm{GDP}^{2}$ and $\mathrm{PM}_{2.5}$ for upper-middle income group (Fig. $1 \mathrm{j}$ ) and dampens the negative relationship between $\mathrm{GDP}^{2}$ and $\mathrm{PM}_{2.5}$ for lower middle-income group (Fig. 1f) and again strengthens positive relationship between GDP and $\mathrm{PM}_{2.5}$ for aggregated income group (Fig. 10), implying that further GDP growth causes environmental degradation emitting $\mathrm{PM}_{2.5}$.

\subsection{Standardized total effect}

The estimated standardised total effect, which is the summation of the standardised direct and indirect effects, enable us to understand the strength of the relationship between the dependent and independent variables. Since AMOS 25 cannot estimate results when there are gaps in the panel data, only a balanced panel data for the period 1992-2018 is considered (for further justifications, see Sect. 3.1).

Table 4 illustrates the results of standardized total effects. In low-income group, GDP growth shows the standardized total negative impact while GDP ${ }^{2}$ growth shows the total significant positive impact on $\mathrm{CO}_{2}$ emission. In interaction effect, GDP interaction with TO shows standardised positive impact while GDP ${ }^{2}$ growth interaction with TO depicts the total significant negative impact, meaning that after attaining a threshold point of economic growth, TO helps to develop the quality of environment in low income countries. $\mathrm{In}^{\mathrm{CH}_{4}}$ emissions, GDP growth has the total negative impact for upper-middle and aggregated data income groups while $\mathrm{GDP}^{2}$ growth has positive impact indicating further economic growth that leads to greater $\mathrm{CH}_{4}$ emissions. But in interaction effect, although TO interaction with GDP growth causes positive impact, its interaction effect with $\mathrm{GDP}^{2}$ shows the significant negative impact on $\mathrm{CH}_{4}$ emissions for both the income groups in support to the EKC. Moreover, in $\mathrm{PM}_{2.5}$ emissions, GDP of upper-middle, high income and aggregated income groups, show significant negative impact while GDP $^{2}$ reveals the positive impact meaning that further economic growth intensifies $\mathrm{PM}_{2.5}$. In interaction effect, although TO interaction with GDP growth demonstrates standardized total positive impact, GDP ${ }^{2}$ interaction with TO depicts the total negative impact on $\mathrm{PM}_{2.5}$ emissions for high income and aggregated income groups.

\section{Discussion}

The impact of the moderation effect of TO differs according to the level of income groups. GDP significantly causes $\mathrm{CO}_{2}$ emissions (see Table 7 in the appendix) for aggregated income groups, while $\mathrm{GDP}^{2}$ has a significant negative impact on reducing $\mathrm{CO}_{2}$ emissions for uppermiddle and low-middle income groups and significant positive impact for low-income group. The moderation effect suggests that TO interaction with GDP reduces $\mathrm{CO}_{2}$ emissions for high income and aggregated income groups while it increases $\mathrm{CO}_{2}$ for low income group, 


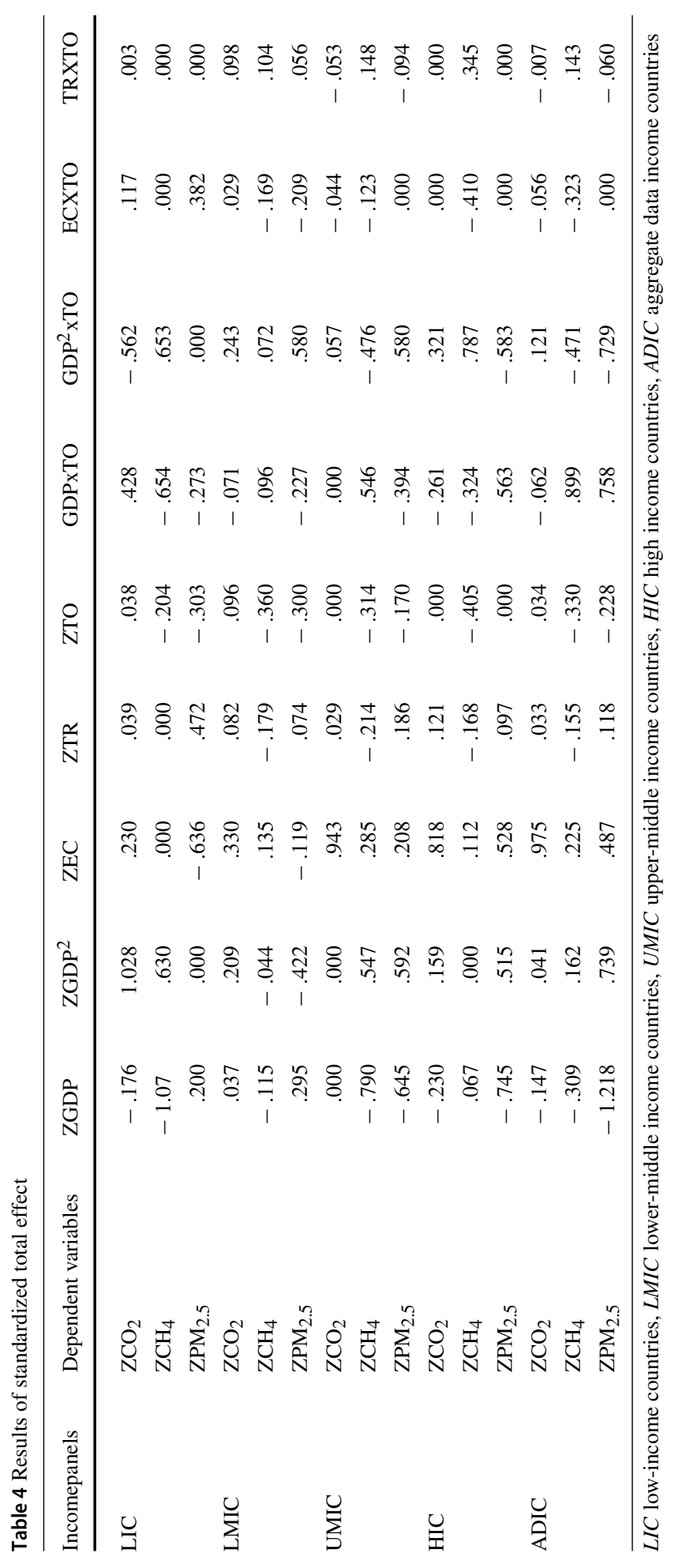


hence aligning with the results of Mahadevan and Sun (2020) for the Belt and Road Countries (BRCs) on the regional level and Ergun and Rivas (2020) for Uruguay on the national level. Furthermore, the results pertaining to the TO interaction with $\mathrm{GDP}^{2}$ growth that increases $\mathrm{CO}_{2}$ emissions for lower-middle, upper-middle, high income and aggregated income groups are in line with the studies of Sin-Yu and Njindan (2019) for Central and Eastern European countries and Bernard and Mandal (2016) for 60 emerging and developing countries (excluding the low income panel).

The impact of $\mathrm{CH}_{4}$ emissions in low-, upper-middle-, and aggregated-income groups is found to be significant, and negative and positive in high-income group. The fact however, that $\mathrm{GDP}^{2}$ causes $\mathrm{CH}_{4}$ emissions for low, upper-middle-, and aggregated-income groups suggests a U-shaped EKC. When TO is interacted with GDP, a positive impact for uppermiddle-, and aggregated-income groups is observed whilst a negative impact on the emissions for low, and high-income groups is established. Conversely, the interaction effect between TO with GDP ${ }^{2}$ shows a significant and positive impact for low- and high-income groups but a negative impact on the emissions for upper-middle-, and aggregated-income groups.

When $\mathrm{PM}_{2.5}$ emissions are considered, $\mathrm{GDP}^{2}$ has significant positive impact on uppermiddle, high income and aggregated income groups implying that further economic growth degrades the quality of environment. However, the interaction effect of TO with GDP reduces $\mathrm{PM}_{2.5}$ for low and upper-middle income groups whilst it increases $\mathrm{PM}_{2.5}$ emissions for high income and aggregated income groups. Moreover, TO interaction with GDP ${ }^{2}$ reduces $\mathrm{PM}_{2.5}$ for high income and aggregated income groups is in line with our hypothesis, however it has significant positive impact on $\mathrm{PM}_{2.5}$ emissions for lower-middle and upper-middle income groups which is in line with the results of Le et al. (2016) for 98 countries, classified into low-, middle- and high-income panels, covering 1990-2013 panel data. The finding of this study thus ascertains the existence of the pollution haven hypothesis $(\mathrm{PHH})$, reiterating the perception that the rich economies relocate their heavily polluting industrial operations to the developing world.

As a major energy consuming sector and growing contributions in global emissions largely in the forms of $\mathrm{CO}_{2}$ and $\mathrm{PM}_{2.5}$ emissions, this study incorporated transportation (TR) in the econometric equation due to its strong influence on the economic growth and environmental pollution nexus. Findings in this study suggest that in the main effect, TR has significant positive impact on both $\mathrm{CO}_{2}$ and $\mathrm{PM}_{2.5}$ emissions for all the income groups while it shows negative impact on $\mathrm{CH}_{4}$ emission. However, in interaction effect, TR has significant negative impact in reducing both $\mathrm{CO}_{2}$ and $\mathrm{PM}_{2.5}$ emissions in the upper-middle and high income countries. This finding is indicative of efficiencies in energy consumption (EC) and adoption of advanced and/or green technologies in these income groups, as pointed out by Frondel et al. (2010), Demirel and Kesidou (2011) and Arvanities and Ley (2013) in the contexts of Germany, the UK and Switzerland respectively. Moreover, TO interaction with EC helps to reduce pollution emissions in lower-middle and upper-middle income countries, and this is indicative of the possibility of successful transfers of better technologies in managing efficiency of EC towards reducing pollutions, as emphasised earlier by World Bank (2007).

\section{Concluding remarks}

"Both theory and evidence suggest that trade promotes growth" (Le et al., 2016, p. 45) and countries prioritizing economic growth based on trade witness degrading environmental quality (Wang et al., 2020a, 2020b, 2020c). 
However, "both theoretical and empirical researchers have provided mixed and conflicting evidence on the effect of trade on economic growth and on the environment" (Hakimi \& Hamdi, 2016, p. 1447). In this study, the relationship between economic growth and environmental degradation in the EKC framework is investigated. A panel data empirical investigation applied to 115 active WTO member countries for the period 1992-2018 is used and the World Bank classifications are followed to study them in three major income groups. The main and interaction effects of TO in the growth-pollution nexus is estimated using Structural equation modelling (SEM), and $\mathrm{CO}_{2}$ emissions and additionally $\mathrm{CH}_{4}$, and $\mathrm{PM}_{2.5}$ emissions as major sources and proxies of environmental degradation are utilized to ensure further robustness of the analysis. The contribution of this study is threefold in that a) a novel methodological approach has been adopted, (b) an investigation of both main and interaction effects of TO has taken place and (c) a combination of three major pollutants to study the growth-pollution nexus in the context of EKC has been considered.

The findings suggest that TO degrades the quality of environment for low- and middleincome countries. When interaction effects were explored, TO interaction with GDP is found to reduce both $\mathrm{CO}_{2}$ and $\mathrm{CH}_{4}$ emissions for high income countries; its interaction with GDP ${ }^{2}$ growth increases both types of emissions, hence implying a U-shaped EKC. In lower-middle income countries, GDP growth has significant positive impact while GDP ${ }^{2}$ growth has significant negative impact on $\mathrm{PM}_{2.5}$ emissions, meaning that further economic growth reduces $\mathrm{PM}_{2.5}$ emissions and hence supports the EKC hypothesis. In both upper-middle, and highincome groups a U-shaped EKC is observed indicating that additional economic growth degrades the quality of environment emitting $\mathrm{PM}_{2.5}$. The interaction between TO and GDP 2 growth shows the significant negative impact in reducing $\mathrm{PM}_{2.5}$ emissions for high income group. Moreover, TO interaction with EC helps to reduce pollution emission in middle income countries by transferring better technologies for efficient use of energy. In addition, the interaction effect of TO with transportation (TR) helps to reduce $\mathrm{CO}_{2}$ emissions by adopting efficiencies in energy consumption and advanced technologies in upper-middle- and highincome groups. Countries in this regard can hope to be benefitted with the upcoming Fourth Industrial Revolution innovations towards facing the world's most tenacious environmental issues (as warned by PWC, 2018).

The evidence produced on the two-way interaction effects suggests that TO dampens the negative relationship between GDP and $\mathrm{CO}_{2}$ for low-income group and strengthens the positive relationship between $\mathrm{GDP}^{2}$ and $\mathrm{CH}_{4}$ for lower-middle income group which, according to the "pollution haven hypothesis" (PHH) (Jun et al., 2020), would be indicative of worsening quality of environment due to liberalization of trade. Moreover, the standardized total effect shows that TO interaction with $\mathrm{GDP}^{2}$ growth increases $\mathrm{CO}_{2}, \mathrm{CH}_{4}$ and $\mathrm{PM}_{2.5}$ emissions in lower-middle income countries; $\mathrm{CO}_{2}$ and $\mathrm{PM}_{2.5}$ emissions in upper-middle income countries, and $\mathrm{CO}_{2}$ and $\mathrm{CH}_{4}$ emissions in high income countries.

In light of the mix of evidence generated in this study, potential expedients of enacting the "enabling environment" and nullifying the "pollution haven hypothesis" (PHH) are proposed. All-out efforts of the high, middle, and low-income countries to improve the quality of their environments can facilitate a better quality of environment to the world inhabitants. It would therefore be necessary that all countries from various income groups come together and establish a common set of environmental policies to cease tricky practices like migrating dirty industrial operations to the developing world. These policies will compel large trading countries like China and the USA to push its partners to adopt more environment friendly practices (Gamso, 2018), e.g., integrating environment-friendly provisions in the trade agreements (Le et al., 2016), and also compel countries seeking larger global market share to follow suit. The common set of policy measures would however require a serious 
attention as earlier initiatives on developing multilateral agreements, e.g., the Doha Climate Change Conference in 2012, and accomplishing the global warming target (below $2{ }^{\circ} \mathrm{C}$ ) of the Paris Agreement of 2015 (Wang et al., 2020a) have shown persistent signs of struggles towards yielding the desired outcomes.

On the policy front, it is commonly argued or typically expected that developed countries should provide financial and technological supports for mitigation and adaptation efforts in developing countries in the wake of the PHH and this seems to have not worked. Realistically, attempts to transform the "enabling environment" (PWC, 2018) such as removing trade barriers for environment-friendly technology, negotiating international agreements on climate change, setting sectoral and sub-sectoral contribution limits, etc. would be required to face the global environmental challenges and support fostering the notion of "green economy". Also, given that open trade does not affect environmental quality uniformly across different income groups (Le et al., 2016), it is imperative that policy measures are tailored so as to take into account the specific country characteristics to improve environmental quality and enhance sustainable economic growth. For example, whether the manufacturers or the consumers would bear the burden of the emission/carbon tax would depend on a country's political system of governance, e.g., as cited in Ren and Chen (2020), the tax burden is borne by manufactures in Chile and customers in Sweden, and either way a similar net environmental outcome is achieved by the country.

The findings of this paper have policy and managerial implications in the national economies and on the global institutional levels in the backdrops of the global pandemic as well as the changing political and economic scenarios in the recent times. For example, the COVID-19 pandemic has channelled more households into the poverty net, and it has raised the possibility of higher $\mathrm{CO}_{2}$ emissions due to more reliance on traditional fossil fuels. Moreover, following short-term reduction in emissions due to severe lockdowns, countries will rapidly bounce back to a trade-led growth path where emissions will significantly rise to exceed the global warming threshold, i.e., "a necessary step towards a green society" (Wang et al., 2020b). Henceforth, the results associated with the mediating role of trade in growthpollution nexus corresponding to different income panels of countries will support reforming current policies and their applications in various initiatives and/or schemes related to "green economy", e.g., to mention a few: (a) The introduction of carbon pricing systems in the USA to secure the Natural Climate Solutions (NCS) including green aviation and clean electricity; (b) The government plan to kick off trading in nationwide emissions trading system (ETS), enhancing sectoral coverages to chemical, petrochemicals, paper and steel in China; (c) The upcoming carbon pricing mechanism in Japan and Taiwan, and similar follow suits in Colombia, Indonesia, Mexico, Thailand and Vietnam between 2022 and 2026; (d) The likely launch of Border Carbon Adjustment Mechanism (BCAM) in the EU, as part of their target to be a "net zero" region by 2050; (e) Potential reformations of policies on trade and the environment in the low- and middle-income countries to applying their nationally defined contributions (NDCs) under the Paris Agreement to achieve climate goals while grabbing opportunities for trades.

The extant literature tends to consider manufacturing, energy, transport and food processing industries as the major pollutants on earth, and often misses out investigating the fashion industry which is believed to be the second most polluting industry globally, accountable for more than the sum of pollution made by maritime shipping and international aviation (UN, 2019). This is an industry which continues to flourish due to its "fast fashion" model of consumerism in the developed economies whereas its manufacturing activities are increasingly relocated in the developing countries, many of which rely pre-dominantly on coal and/or gas. Since "the past two years have witnessed unprecedented global shocks from deepening trade 
tensions related to the COVID-19 pandemic" (Brenton \& Chemutai, 2021, p. 8) and henceforth countries are projected to bounce back stronger in the post-COVID recovery stage, at an estimated rate of 8.0-11.0 percent rise in the volume of world merchandise trade in 2021 (WTO 2021a, 2021b), it is necessary to investigate the role of the fashion industry in the growth-pollution nexus, aiming to contribute to the potential formulations of policy measures to ensure that garments are manufactured and consumed as ethically and sustainably as possible. Moreover, since transportation (TR) plays a significant role in global pollutions due to its inter-connectivity with all major industrial activities and operations, it would be vital to investigate the moderation role of TR in an EKC framework.

As an empirical analysis on the nexus of economic growth and environment has the privilege of considering a wide variety of sources of pollution such as manufacturing, transport, agriculture, food processing, etc., arguably a possible limitation of this research could be the parsimonious specification of the empirical model. In this context, a more holistic analysis can be made on the degree and nature of polluting activities as well as the corrective measures that are applied in various income panels of countries to produce insightful evidence on the impact of the synergetic relationships between urban form, land-use, built environment, transportation, and environmental degradation, in pursuit of a collective convergence of countries to green economic growth. Henceforth, potential future research can also be directed at aspects of spatial planning and its ensuing implication for the environment.

\section{Appendix}

See Tables 5, 6, 7 and 8 . 


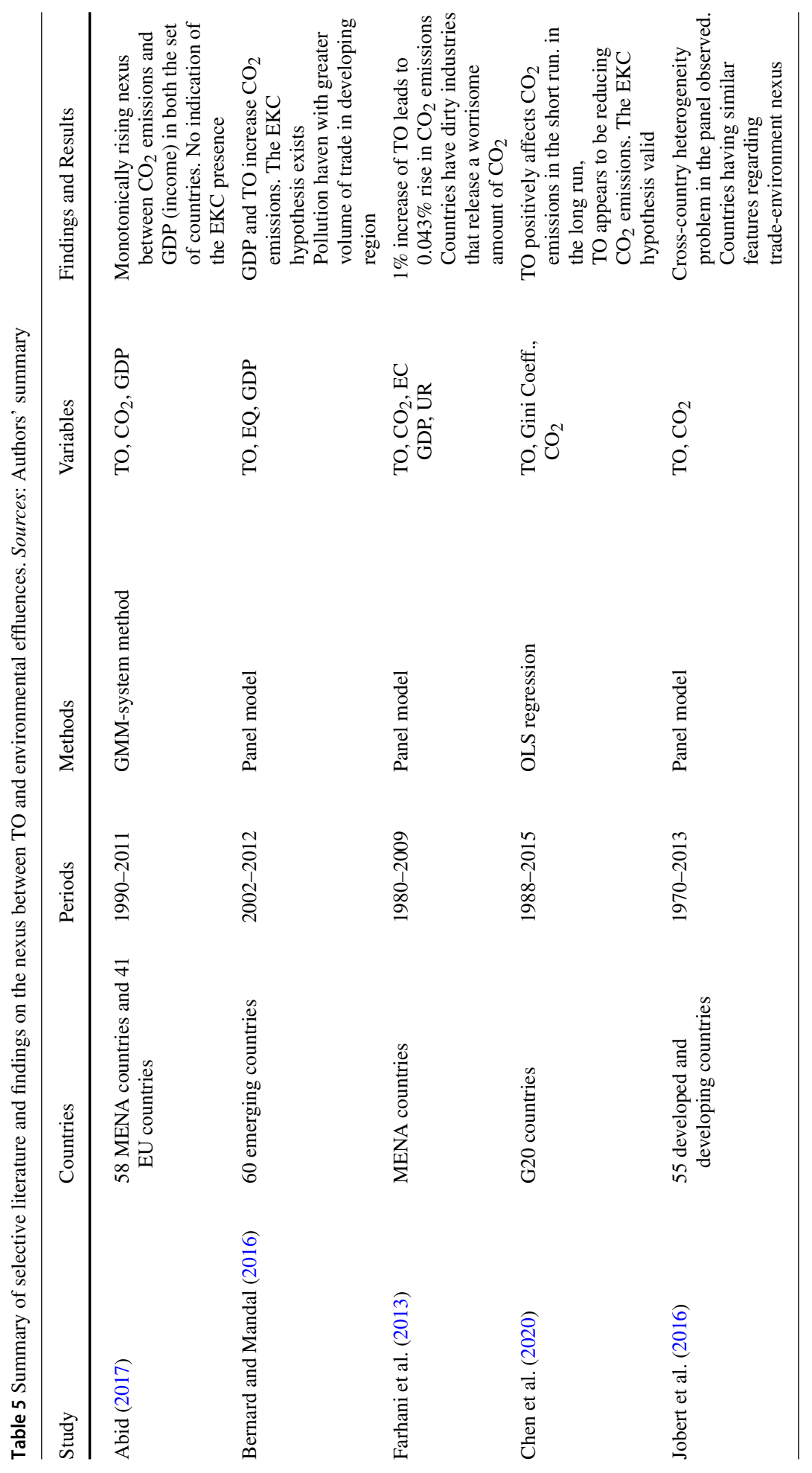




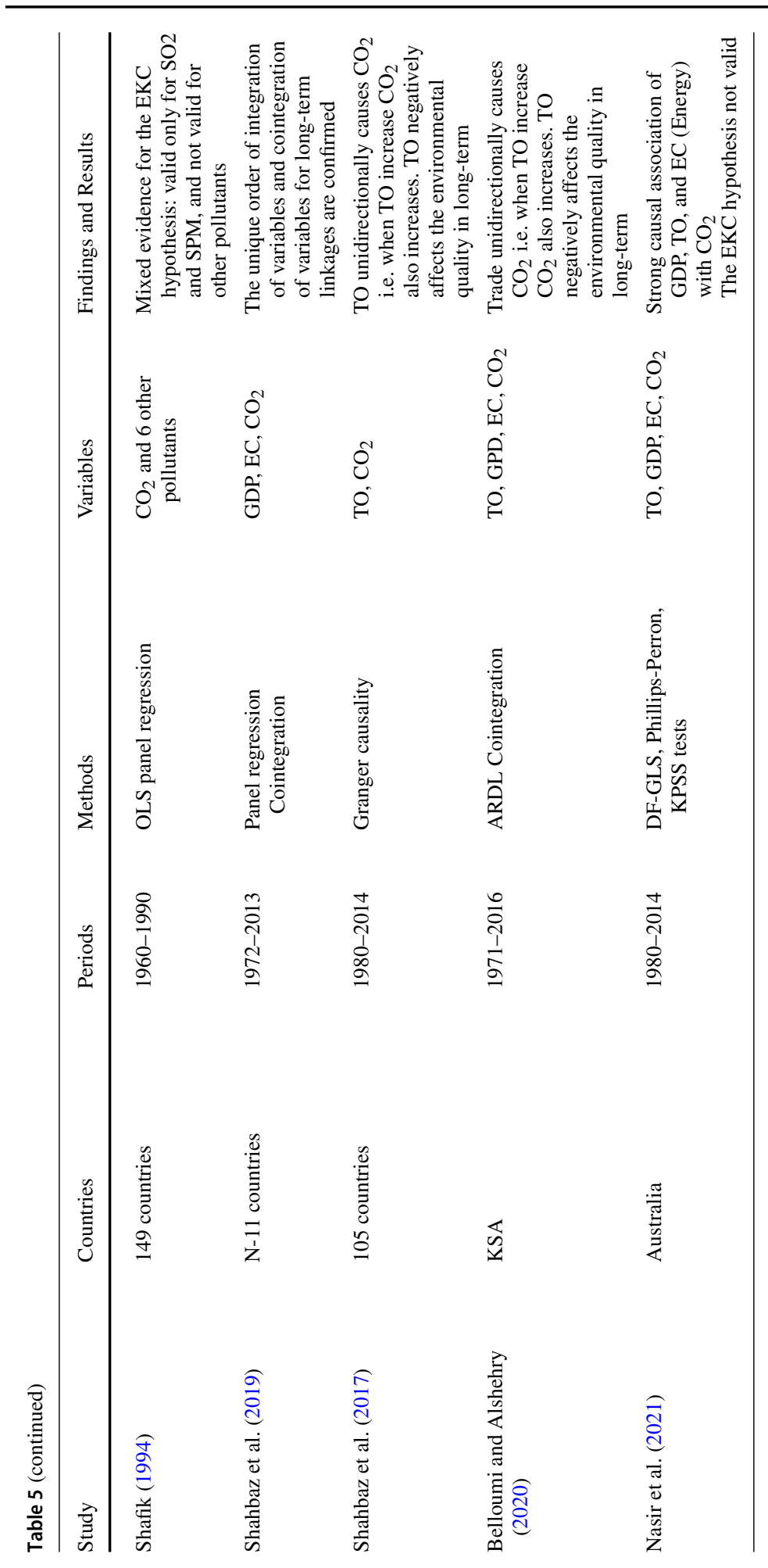




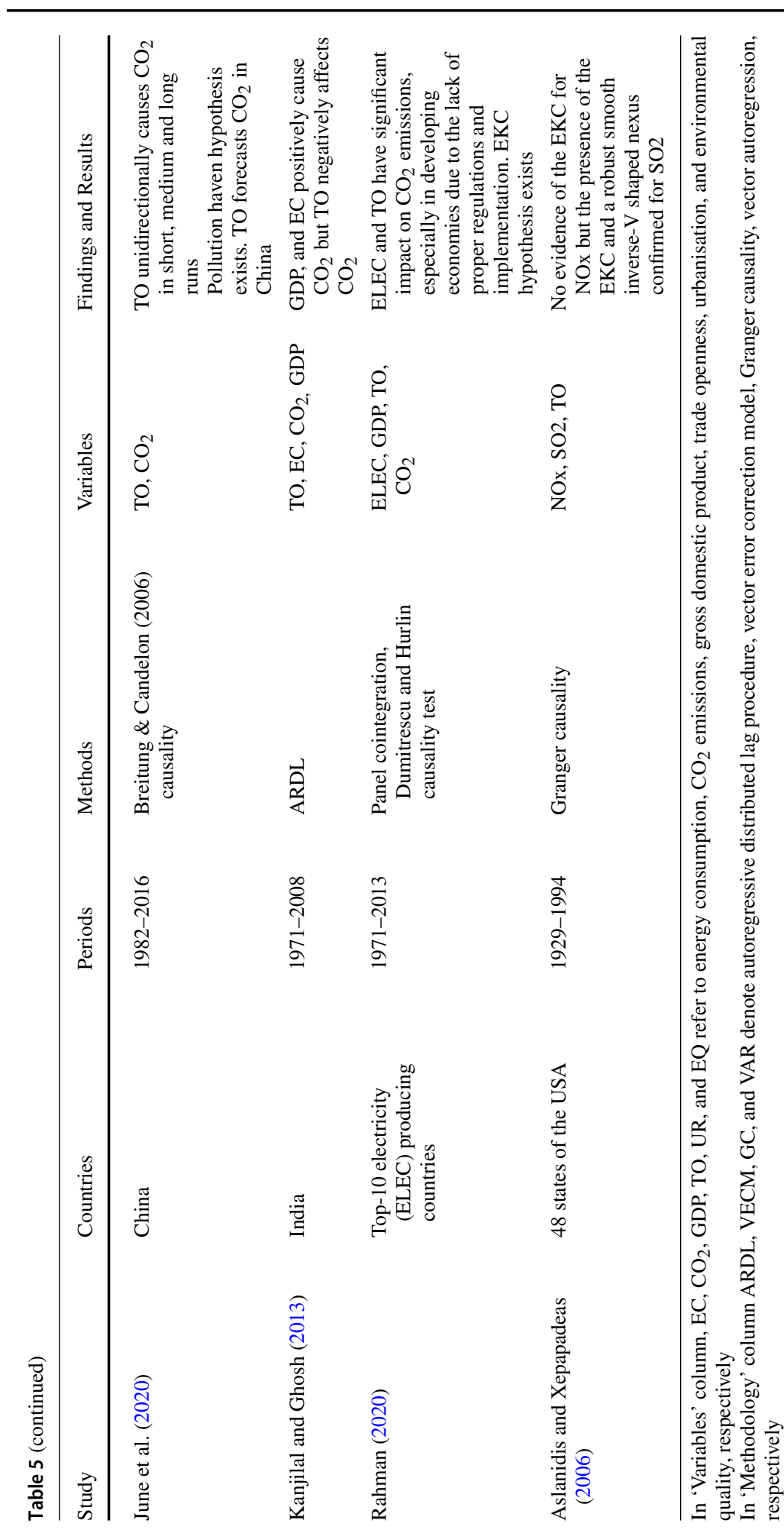




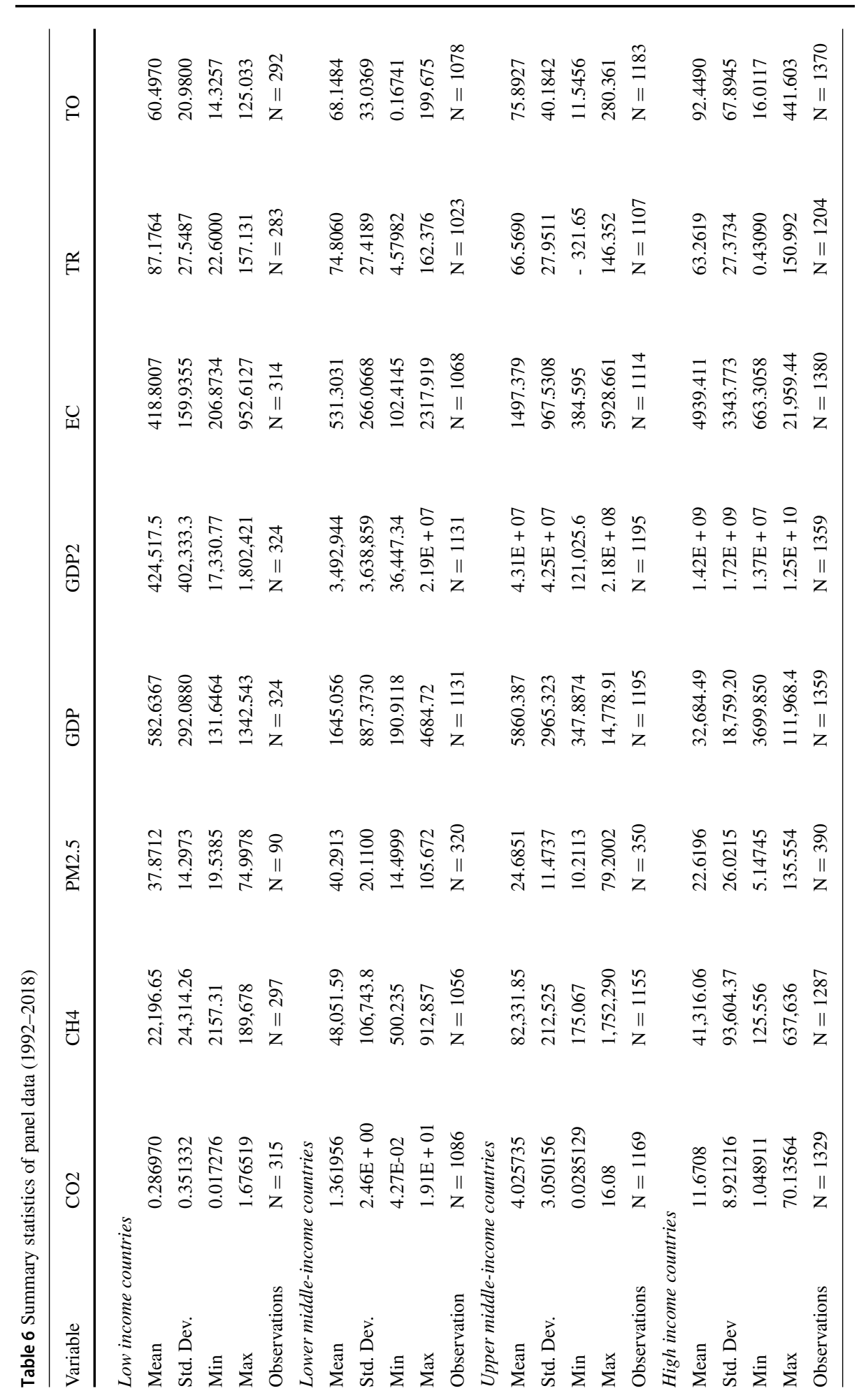




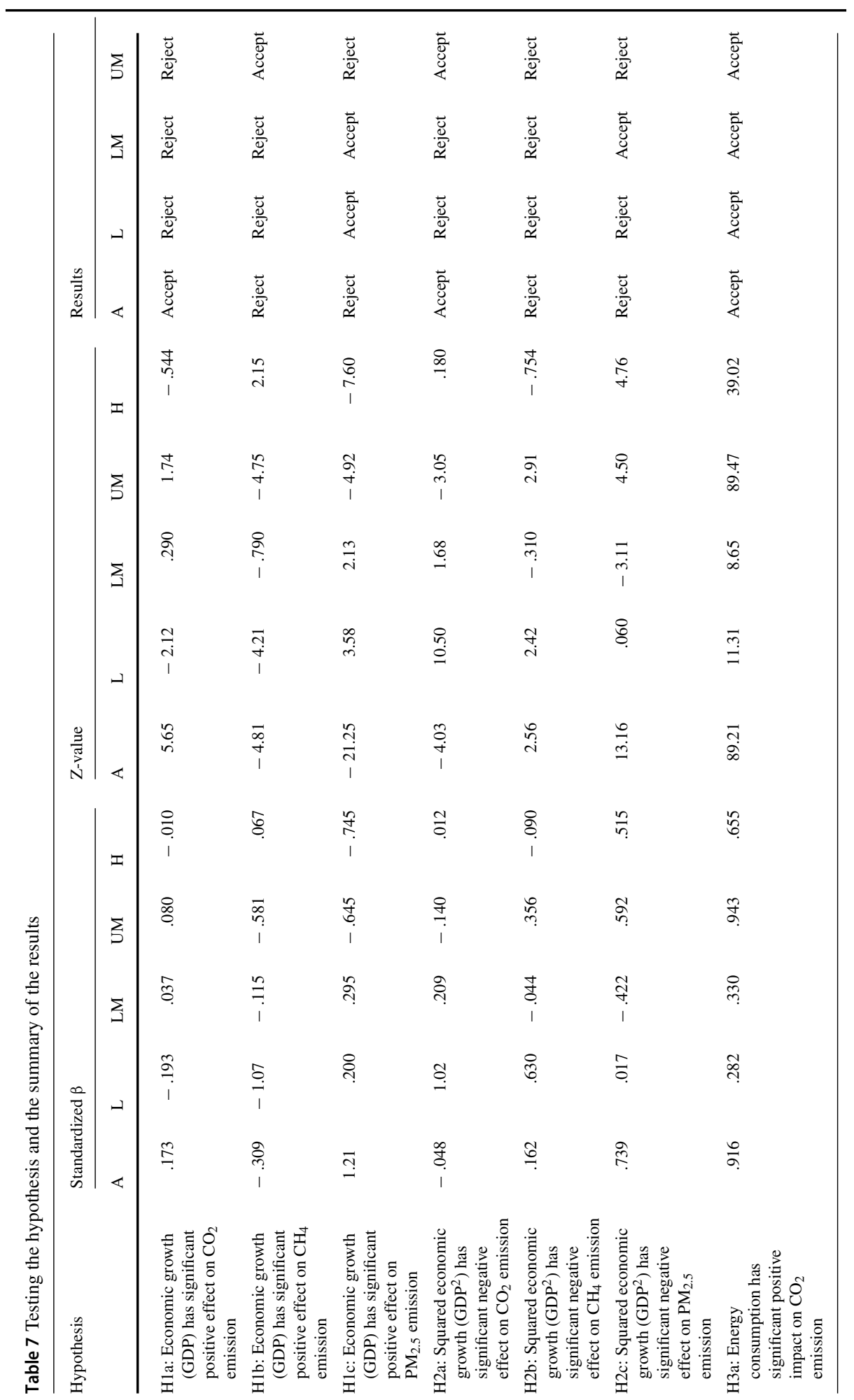




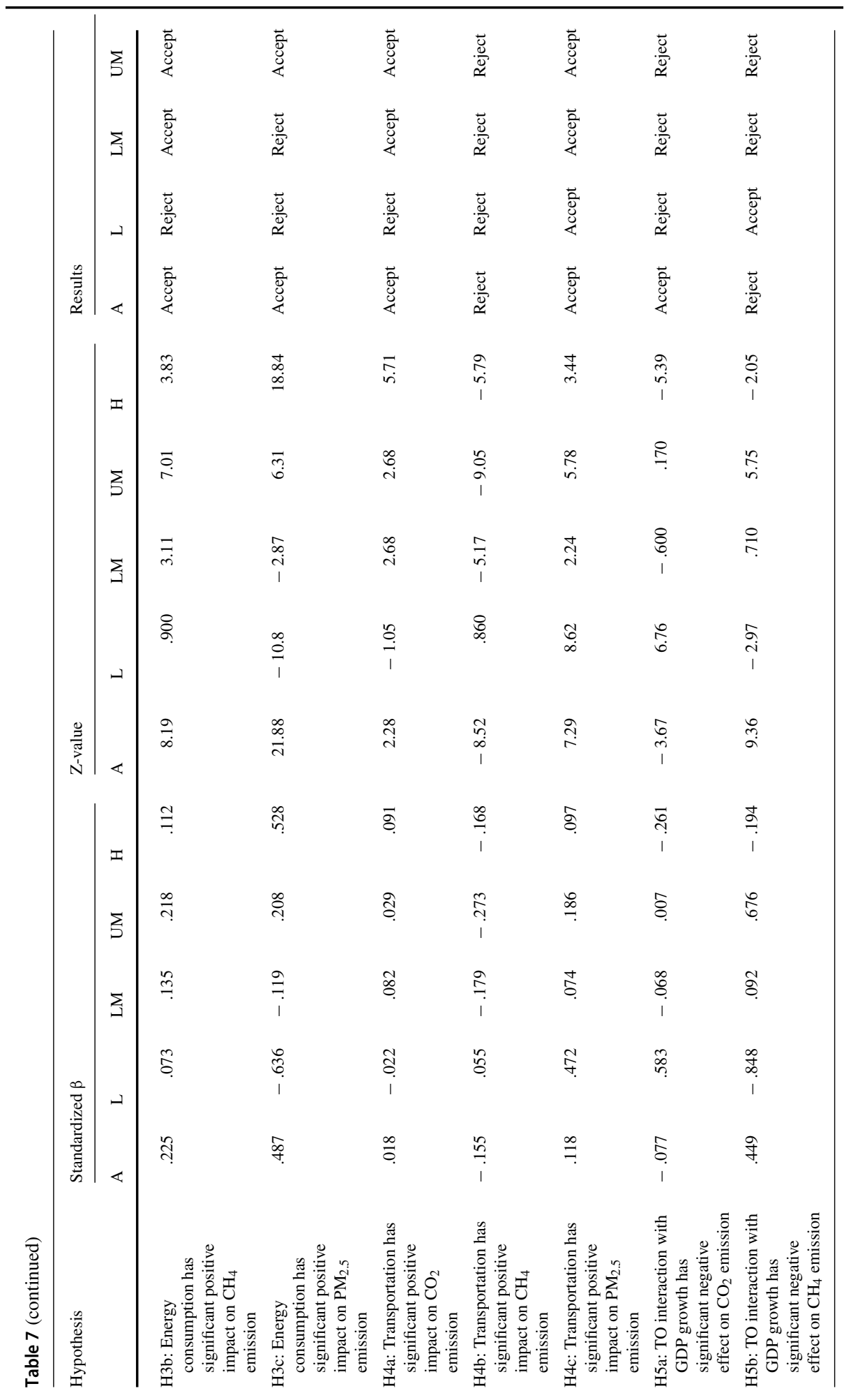




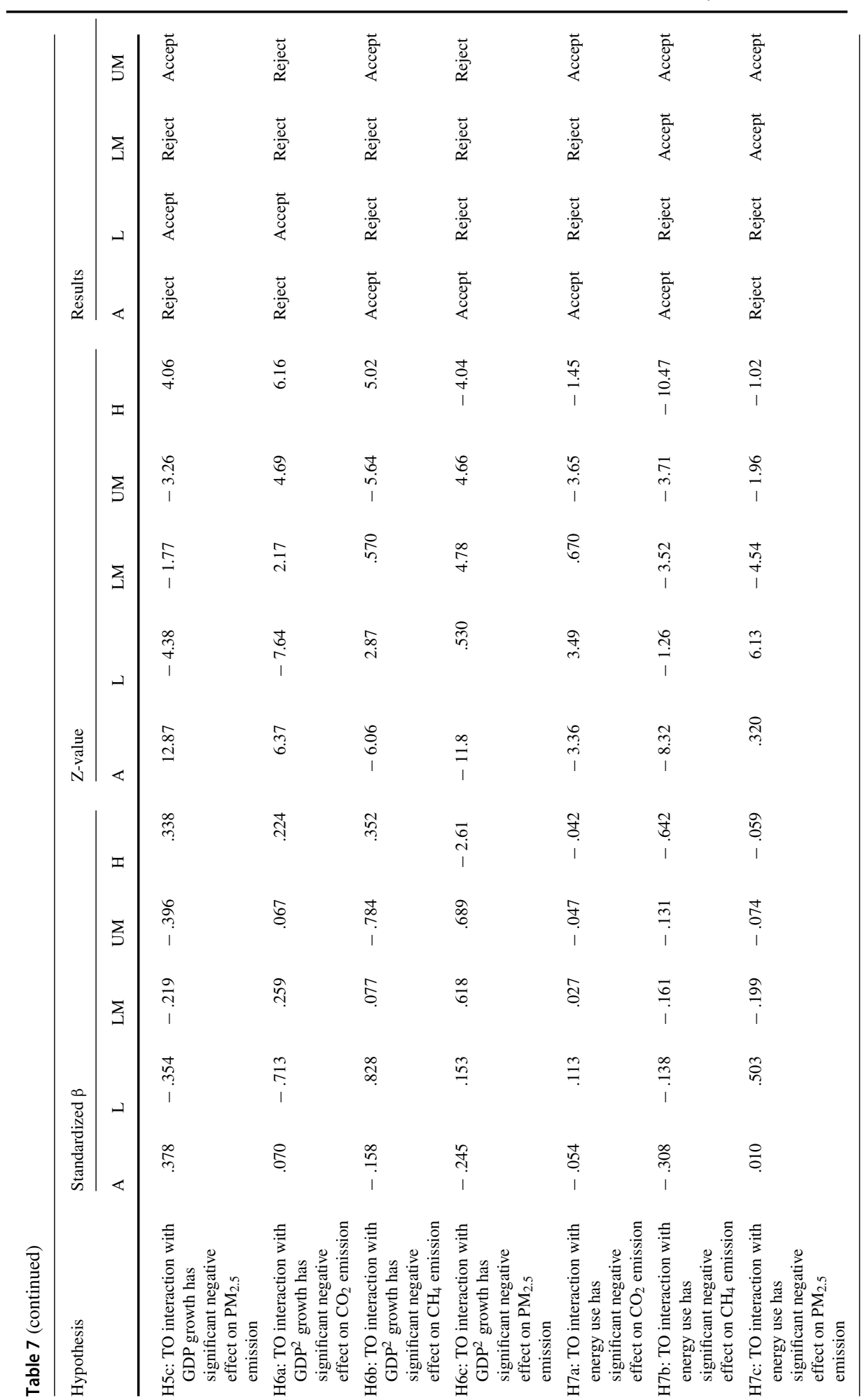




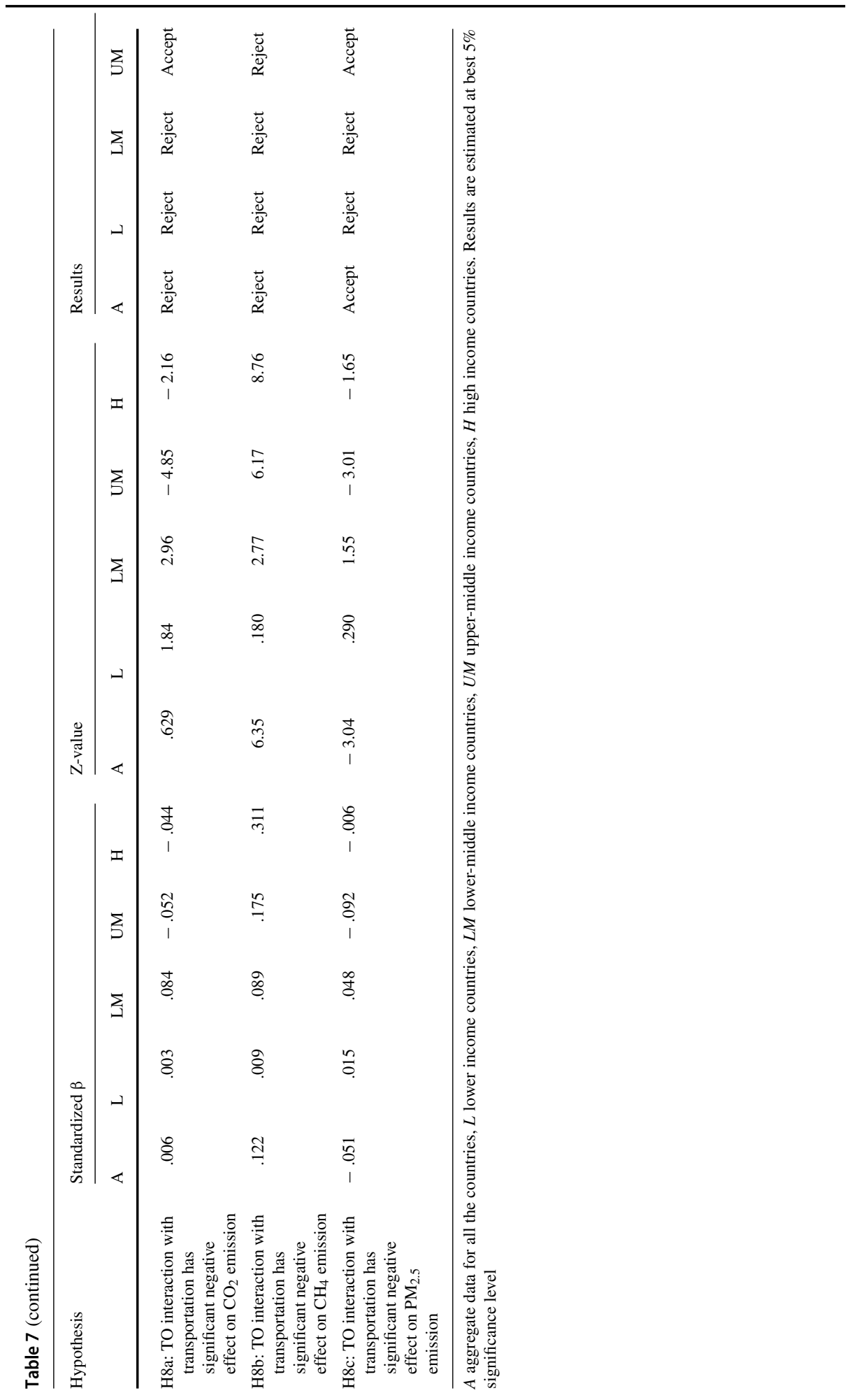


Table 8 The list of investigated countries based on their income level

Low-income countries: Benin, Congo Dem. Rep., Ethiopia, Mozambique, Nepal, Senegal, Tanzania, Togo and Zimbabwe

Lower-middle-income countries: Angola, Armenia, Bangladesh, Bolivia, Cambodia, Cameroon, Congo Rep., Cote d'Ivoire, Egypt, El Salvador, Ghana, Guatemala, Honduras, India, Indonesia, Jordan, Kenya, Kyrgyzstan, Mongolia, Morocco, Myanmar, Nicaragua, Nigeria, Pakistan, Philippines, Sri Lanka, Sudan, Syrian Arab Republic, Tajikistan, Tunisia, Yemen and Zambia

Upper-middle-income countries: Albania, Algeria, Argentina, Azerbaijan, Belarus, Botswana, Brazil, Bulgaria, China, Colombia, Costa Rica, Croatia, Dominican Republic, Ecuador, Gabon, Guyana, Iran, Jamaica, Kazakhstan, Lebanon, Libya, Malaysia, Mauritius, Mexico, Namibia, Panama, Paraguay, Peru, Romania, Russia, South Africa, Suriname, Thailand, Turkey, Venezuela

High-income countries: Australia, Austria, Bahrain, Belgium, Brunei, Canada, Chile, Cyprus, Czech Republic, Denmark, Estonia, Finland, France, Germany, Greece, Hungary, Iceland, Italy, Japan, Korea Republic, Kuwait, Luxembourg, Malta, Netherlands, New Zealand, Norway, Oman, Poland, Portugal, Qatar, Saudi Arabia, Singapore, Spain, Sweden, Switzerland, Trinidad and Tobago, UK, US and Uruguay

\section{References}

Abbasi, F., \& Riaz, K. (2016). $\mathrm{CO}_{2}$ emissions and financial development in an emerging economy: An augmented VAR approach. Energy Policy, 90, 102-114. https://doi.org/10.1016/j.enpol.2015.12.017

Abdouli, M., \& Hammami, S. (2016). Investigating the causality links between environmental quality, foreign direct investment and economic growth in MENA countries. International Business Review, 26(2), 264-278. https://doi.org/10.1016/j.ibusrev.2016.07.004

Abid, M. (2017). Does economic, financial and institutional developments matter for environmental quality? A comparative analysis of EU and MEA countries. Journal of Environmental Management, 188, 183-194. https://doi.org/10.1016/j.jenvman.2016.12.007

Adedoyin, F., Ozturk, I., Abubakar, I., Kumeka, T., Folarin, O., \& Bekun, F. V. (2020). Structural breaks in $\mathrm{CO} 2$ emissions: Are they caused by climate change protests or other factors? Journal of Environmental Management, 266, 110628. https://doi.org/10.1016/j.jenvman.2020.110628

Al-Mulali, U., Solarin, S. A., Sheau-Ting, L., \& Ozturk, I. (2016). Does moving towards renewable energy cause water and land inefficiency? An empirical investigation. Energy Policy, 93, 303-314. https://doi. org/10.1016/j.enpol.2016.03.023

Amar, A. B. (2021). Economic growth and environment in the United Kingdom: Robust evidence using more than 250 years data. Environmental Economics and Policy Studies, 23, 667-681. https://doi.org/10.1007/ s10018-020-00300-8

Arvanitis, S., \& Ley, M. (2013). Factors determining the adoption of energy-saving technologies in Swiss firms: An analysis based on micro data. Environmental and Resource Economics, 54(3), 389-417.

Aslanidis, N., \& Xepapadeas, A. (2006). Smooth transition pollution-income paths. Ecological Economics, 57(2), 182-189.

Balezentis, T., Liobikien, G., Streimikiene, D., \& Sun, K. (2020). The impact of income inequality on consumption-based greenhouse gas emissions at the global level: A partially linear approach. Journal of Environmental Management, 267, 1-13.

Belloumi, M., \& Alshehry, A.(2020). The Impact of International Trade on Sustainable Development in Saudi Arabia. Sustainability, 12, 1-17. https://doi.org/10.3390/su12135421

Bergasse, E., Paczynski, W., Dabrowski, M., \& Wulf, L. (2013). The relationship between energy and socioeconomic development in the Southern and Eastern Mediterranean. Working Paper. CASE Network Reports, Center for Social and Economic Research (CASE).

Bernard, J., \& Mandal, S. K. (2016). The impact of trade openness on environmental quality: An empirical analysis of emerging and developing economies. WIT Transactions on Ecology and the Environment. https://doi.org/10.2495/EID160181

Bollen, K. A., \& Noble, M. D. (2011). Structural equation models and the quantification of behavior. PNAS, 108(3), 15639-15646. https://doi.org/10.1073/pnas.1010661108 
Bollen, K. A., \& Pearl, J. (2013). Eight myths about causality and structural equation models. In S. L. Morgan (Ed.), Handbook of causal analysis for social research (pp. 301-328). Springer.

Brenton, P., \& Chemutai, V. (2021). The trade and climate change nexus: the urgency and opportunities for developing countries. World Bank Publication. [Online] https://openknowledge.worldbank.org/handle/ $10986 / 36294$.

Brommer, J. E., Karell, P., Ahola, K., \& Karstinen, T. (2014). Residual correlations, and not individual properties, determine a nest defense boldness syndrome. Behavioral Ecology, 25(4), 802-812. https://doi.org/ 10.1093/beheco/aru057

Browne, M. W., \& Cudeck, R. (1993). Alternative ways of assessing model fit. Sage Focus Editions, 154, 136-136.

Busa, J. H. M. (2013). Dynamite in the EKC tunnel? Inconsistencies in resource stock analysis under the environmental Kuznets curve hypothesis. Ecological Economics, 94, 116-126.

Caviglia-Harris, J. L., Chambers, D., \& Kahn, J. R. (2009). Taking the "U” out of Kuznets: A comprehensive analysis of the EKC and environmental degradation. Ecological Economics, 68(4), 1149-1159.

Chen, C. F., \& Myagmarsuren, O. (2013). Exploring the moderating effects of value offerings between market orientation and performance in tourism industry. International Journal of Tourism Research, 15(6), 595-610.

Chen, J., Xian, Q., Zhou, J., \& Li, D. (2020). Impact of income inequality on CO2 emissions in G20 countries. Journal of Environmental Management, 271, 110987. https://doi.org/10.1016/j.jenvman.2020.110987

Chen, Q., Loschel, A., Pei, J., Peters, G., Xue, J., \& Zhao, Z. (2019). Processing trade, foreign outsourcing and carbon emissions in China. Structural Change and Economic Dynamics, 49, 1-12. https://doi.org/ 10.1016/j.strueco.2019.03.004

Chen, Y., \& Fang, Z. (2018). Industrial electricity consumption, human capital investment and economic growth in Chinese cities. Economic Modelling, 69, 205-219.

Cohen, J., Cohen, P., West, S., \& Aiken, L. (2003). Applied multiple regression/correlation analysis for the behavioral sciences, 3rd edn. Mahwah, NJ: Lawrence Erlbaum.

Datta, A., Das, S., Manjunath, K. R., \& Adhya, T. K. (2012). Comparison of two methods for the estimation of greenhouse gas flux from rice ecosystems in India. Greenhouse Gas Measurement and Management, 2(1), 43-49.

Demirel, P., \& Kesidou, E. (2011). Stimulating different types of eco-innovation in the UK: Government policies and firm motivations. Ecological Economics, 70(8), 1546-1557.

Dubey, R., Gunasekaran, A., Childe, S. J., Luo, Z., Wamba, S. F., Roubaud, D., \& Foropon, C. (2018). Examining the role of big data and predictive analytics on collaborative performance in context to sustainable consumption and production behaviour. Journal of Cleaner Production, 196, 1508-1521.

EEA. (2020). Train or plane? Transport and environment report 2020. European Environment Agency (EEA). EEA Report No. 19/2020.

Emerson, J. W., Esty, D. C., Srebotnjak, T., \& Connett, D. (2015). Exploring trade \& the environment an empirical examination of trade openness and national environmental performance. Yale Center for Environmental Law \& Policy, US: Yale.

EPA. (2017). Sources of greenhouse gas emission. Overview of greenhouse gases. The United States Environmental Protection Agency (EPA).

EPA. (2021). Inventory of US greenhouse gas emissions and sinks, 1990-2019. Sources of greenhouse gas emission. Overview of greenhouse gases. Report published on April 14, 2021. The United States Environmental Protection Agency (EPA).

Ergun, S. J., \& Rivas, M. F. (2020). Testing the environmental Kuznets curve hypothesis in Uruguay using ecological footprint as a measure of environmental degradation. International Journal of Energy Economics and Policy, 10(4), 473-485.

Espoir, D. K., \& Sunge, R. (2021). Co2 emissions and economic development in Africa: Evidence from a dynamic spatial panel model. ZBW-Leibniz Information Centre for Economics, Kiel, Hamburg.

Fang, Z., Huang, B., \& Yang, Z. (2018). How does trade openness affect the environmental Kuznets curve?. Economics, Environment, Industry And Trade. Retrieved on July 13, 2020 from https://www.asiapathwaysadbi.org/2018/10/how-does-trade-openness-affect-the-environmental-kuznets-curve/

Farhadi, M. (2015). Transport infrastructure and long-run economic growth in OECD countries. Transportation Research Part A: Policy and Practice, 74(C), 73-90. https://doi.org/10.1016/j.tra.2015.02.006

Farhani, S., Shahbaz, M., \& Arouri, M. E. H. (2013). Panel analysis of $\mathrm{CO}_{2}$ emissions, GDP, energy consumption, trade openness and urbanization for MENA countries. MPRA Paper. Retrieved on July 12, 2019 from https://mpra.ub.uni-muenchen.de/49258/1/MPRA_paper_49258.pdf 
Forabosco, F., Chitchyan, Z., \& Mantovani, R. (2017). Methane, nitrous oxide emissions and mitigation strategies for livestock in developing countries: A review. South African Journal of Animal Science, 47(3), 268-280.

Frondel, M., Ritter, N., Schmidt, C. M., \& Vance, C. (2010). Economic impacts from the promotion of renewable energy technologies: The German experience. Energy Policy, 38, 4048-4056.

Gamso, J. (2018). Is China worsening the developing world's environmental crisis?. The Conversation, United Kingdom, August 22. Retrieved on July 19, 2020 from https://theconversation.com/is-china-worseningthe-developing-worlds-environmental-crisis-100284

Grossman, G. M., \& Krueger, A. B. (1995). Economic growth and the environment. Quarterly Journal of Economics, 110, 353-377.

Hakimi, A., \& Hamdi, H. (2016). Trade liberalisation, FDI inflows, environmental quality and economic growth: A comparative analysis between Tunisia and Morocco. Renewable and Sustainable Energy Reviews, 58, 1-13.

Halkos, G. E., \& Polemis, M. L. (2018a). The impact of economic growth on environmental efficiency of the electricity sector: A hybrid window DEA methodology for the USA. Journal of Environmental Management, 211, 334-346. https://doi.org/10.1016/j.jenvman.2018.01.067

Hasan, S. F., Lings, I., Neale, L., \& Mortimer, G. (2014). The role of customer gratitude in making relationship marketing investments successful. Journal of Retailing and Consumer Services, 21(5), 788-796.

He, Z., Xu, S., Shen, W., Long, R., \& Chen, H. (2017). Impact of urbanization on energy related $\mathrm{CO}_{2}$ emission at different development levels: Regional difference in China based on panel estimation. Journal of Cleaner Production, 140, 1719-1730.

Hu, L.-T., \& Bentler, P. M. (1998). Fit indices in covariance structure modeling: Sensitivity to underparameterized model misspecification. Psychological Methods, 3(4), 424.

Inglesi-Lotz, R., \& Bohlmann, J. (2014). Environmental Kuznets curve in South Africa: To confirm or not to confirm?. Prepared for EcoMod. Bali, Indonesia.

Jalil, A., \& Feridun, M. (2011). The impact of growth, energy and financial development on the environment in China: A cointegration analysis. Energy Economics, 33(2), 284-291.

Jalil, A., \& Mahmud, S. F. (2009). Environment Kuznets curve for $\mathrm{CO}_{2}$ emissions: A cointegration analysis for China. Energy Policy, 37(12), 5167-5172.

Jaunky, V. C. (2011). The $\mathrm{CO}_{2}$ emissions-income nexus: Evidence from rich countries. Energy Policy, 39(3), 1228-1240.

Jayanthakumaran, K., Verma, R., \& Liu, Y. (2012). $\mathrm{CO}_{2}$ emissions, energy consumption, trade and income: A comparative analysis of China and India. Energy Policy, 42, 450-460.

Jobert, T., Karanfil, F., \& Tykhonenko, A. (2016). Trade and environment: Further empirical evidence from heterogeneous panels using aggregate data. Working Papers-01295613, HAL.

Jun, W., Mahmood, H., \& Zakaria, M. (2020). Impact of trade openness on environment in China. Journal of Business Economics and Management, 21(4), 1185-1202.

Kanjilal, K., \& Ghosh, S. (2013). Environmental Kuznet's curve for India: Evidence from tests for cointegration with unknown structuralbreaks. Energy Policy, 56, 509-515.

Kasman, A., \& Duman, Y. S. (2015). $\mathrm{CO}_{2}$ emissions, economic growth, energy consumption, trade and urbanization in new EU member and candidate countries: A panel data analysis. Economic Modelling, 44, 97-103.

Kassouri, Y., \& Altintas, H. (2020). Human well-being versus ecological footprint in MENA countries: A trade-off. Journal of Environmental Management, 263, 1-16.

Katircioğlu, S. T., \& Taşpinar, N. (2017). Testing the moderating role of financial development in an environmental Kuznets curve: Empirical evidence from Turkey. Renewable and Sustainable Energy Reviews, 68, 572-586. https://doi.org/10.1016/j.rser.2016.09.127

Kijima, M., Nishide, K., \& Ohyama, A. (2010). Economic models for the environmental Kuznets curve: A survey. Journal of Economic Dynamics \& Control, 34, 1187-1201.

Kim, D., Suen, Y., \& Lin, S. (2019). Carbon dioxide emissions and trade: Evidence from disaggregate trade data. Energy Economics, 78, 13-28. https://doi.org/10.1016/j.eneco.2018.08.019

Le, T.-H., Chang, Y., \& Park, D. (2016). Trade openness and environmental quality: International evidence. Energy Policy, 92, 45-55.

Lean, H. H., Huang, W., \& Hong, J. (2014). Logistics and economic development: Experience from China. Transport Policy, 32, 96-104.

Li, G., Fang, C., Wang, S., \& Sun, S. (2016a). The effect of economic growth, urbanization, and industrialization on fine particulate matter $\left(\mathrm{PM}_{2.5}\right)$ concentrations in China. Environmental Science \& Technology, 50(21), 11452-11459.

Li, T., Wang, Y., \& Zhao, D. (2016b). Environmental Kuznets curve in China: New evidence from dynamic panel analysis. Energy Policy, 91, 138-147. https://doi.org/10.1016/j.enpol.2016.01.002 
Liddle, B., \& Lung, S. (2013). The long-run causal relationship between transport energy consumption and GDP: Evidence from heterogeneous panel methods robust to cross-sectional dependence. Economics Letters, 121(3), 524-527.

Lin, J., Shen, Y., Li, X., \& Hasnaoui, A. (2021). BRICS carbon neutrality target: Measuring the impact of electricity production from renewable energy sources and globalization. Journal of Environmental Management, 298, 113460. https://doi.org/10.1016/j.jenvman.2021.113460

MacCallum, R. C., \& Austin, J. T. (2000). Applications of structural equation modeling in psychological research. Annual Review of Psychology, 51, 201-226.

Mahadevan, R., \& Sun, Y. (2020). Effects of foreign direct investment on carbon emissions: Evidence from China and its Belt and Road countries. Journal of Environmental Management, 276, 1-9.

Masi, D., Kumar, V., Garza-Reyes, J. A., \& Godsell, J. (2018). Towards a more circular economy: Exploring the awareness, practices, and barriers from a focal firm perspective. Production Planning \& Control, 29(6), 539-550.

Mishra, M. K. (2020). The Kuznets curve for the sustainable environment and economic growth. EconStor Preprints 216734, ZBW-Leibniz Information Centre for Economics.

Nasir, M. A., Canh, N. P., \& Le, T. N. L. (2021). Environmental degradation \& role of financialisation, economic development, industrialisation and trade liberalisation. Journal of Environmental Management, 277, 111471. https://doi.org/10.1016/j.jenvman.2020.111471

Nasr, A. B., Gupta, R., \& Sato, J. R. (2015). Is there an environmental Kuznets curve for South Africa? A Co-summability approach using a century of data. Energy Economics, 52, 136-141.

NOAA (2021). Despite pandemic shutdowns, carbon dioxide and methane surged in 2020. Research News of the United States National Oceanic and Atmospheric Administration (NOAA).

Onafowora, O. A., \& Owoye, O. (2014). Bounds testing approach to analysis of the environment Kuznets curve hypothesis. Energy Economics, 44, 47-62.

Panayotou, T. (1993). Empirical tests and policy analysis of environmental degradation at different stages of economic development. Working Paper WP238, Technology and Employment Programme, ILO, Geneva.

Pothen, F., \& Welsch, H. (2019). Economic development and material use. Evidence from international panel data. World Development, 115, 107-119. https://doi.org/10.1016/j.worlddev.2018.06.008

PWC. (2018). Fourth industrial revolution for the earth: Harnessing artificial intelligence for the earth. Pricewatercoopers publication. January 2018 edition.

Rafindadi, A. A., \& Usman, O. (2019). Globalization, energy use, and environmental degradation in South Africa: Startling empirical evidence from the Maki-cointegration test. Journal of Environmental Management, 244, 265-275. https://doi.org/10.1016/j.jenvman.2019.05.048

Rahman, M. M. (2020). Environmental degradation: The role of electricity consumption, economic growth and globalisation. Journal of Environmental Management, 253, 109742. https://doi.org/10.1016/j.jenvman. 2019.109742

Ren, J., Hu, J., \& Chen, X. (2020). The effect of production- versus consumption-based emission tax under demand uncertainty. International Journal of Production Economics, 219(1), 82-98. https://doi.org/10. 1016/j.ijpe.2019.05.009

Richter, N. F., Sinkovics, R. R., Ringle, C. M., \& Schlägel, C. (2016). A critical look at the use of SEM in international business research. International Marketing Review, 33(3), 376-404. https://doi.org/10. 1108/IMR-04-2014-0148

Sam, A. G., \& Zhang, X. (2020). Value relevance of the new environmental enforcement regime in China. Journal of Corporate Finance, 62, 101573. https://doi.org/10.1016/j.jcorpfin.2020.101573

Sarkodie, S. A., \& Strezov, V. (2018). Empirical study of the environmental Kuznets curve and environmental sustainability curve hypothesis for Australia, China, Ghana and USA. Journal Cleaner Production, 201, 98-110.

Selden, T. M., \& Song, D. (1995). Neoclassical growth, the J curve for abatement and the inverted U curve for pollution. Journal of Environmental Economics and Management, 29(2), 162-168.

Shafik, N. (1994). Economic development and environmental quality: An econometric analysis. Oxford Economic Papers, 46, 757-773.

Shafik, N., \& Bandyopadhyay, S. (1992). Economic growth and environmental quality: Time series and crosscountry evidence. Background Paper for World Development Report 1992. World Bank, Washington, DC.

Shah, R., \& Goldstein, S. M. (2006). Use of structural equation modeling in operations management research: Looking back and forward. Journal of Operations Management, 24(2), 148-169.

Shahbaz, M. (2019). Globalization-emissions nexus: Testing the EKC hypothesis in Next-11 countries. Global Business Review. https://doi.org/10.1177/0972150919858490 
Shahbaz, M., Nasreen, S., Ahmed, K., \& Hammoudeh, S. (2017). Trade openness-carbon emissions nexus: The importance of turning points of trade openness for country panels. Energy Economics, 61, 221-232.

Shahbaz, M., Tiwari, A. K., \& Nasir, M. (2013). The effects of financial development, economic growth, coal consumption and trade openness on $\mathrm{CO}_{2}$ emissions in South Africa. Energy Policy, 61, 1452-1459.

Sin-Yu, H., \& Njindan, I. B. (2019). Trade openness and carbon emissions: Evidence from central and eastern European countries. Review of Economics, 70(1), 41-67.

Song, M., Zhu, S., Wang, J., \& Zhao, J. (2019). Share green growth: Regional evaluation of green output performance in China. International Journal of Production Economics, 219, 152-163. https://doi.org/ 10.1016/j.ijpe.2019.05.012

Stein, C. M., Morris, N. J., \& Nocl, N. L. (2017). Structural equation modelling. In Robert C. Elston et al. (Ed.), Statistical human genetics: Methods and protocols, methods in molecular biology, vol. 850, https:// doi.org/10.1007/978-1-61779-555-8_27

Umar, M., Ji, X., Kirikkaleli, D., \& Xu, Q. (2020). COP21 Roadmap: Do innovation, financial development, and transportation infrastructure matter for environmental sustainability in China? Journal of Environmental Management, 271, 111026. https://doi.org/10.1016/j.jenvman.2020.111026

UN (United Nations). (2019). UN launches drive to highlight environmental cost of staying fashionable. UN News. Retrieved on March 25, 2019 from https://news.un.org/en/story/2019/03/1035161.

UNEP. (2021). Global methane assessment: Benefits and costs of mitigating methane emissions. Joint Report of the United Nations Environment Programme (UNEP) and Climate and Clean Air Coalition. Nairobi: United Nations Environment Programme.

Vehmas, J., Luukkanen, J., \& Kaivo-oja, J. (2007). Linking analyses and environmental Kuznets curves for aggregated material flows in the EU. Journal of Cleaner Production, 15(17), 1662-1673.

Wang, S., \& Ge, M. (2019). Everything you need to know about the fastest-growing source of global emissions: Transport. World Resources Institute, USA, October 16.

Wang, L., Chang, H.-L., Rizvi, S. K. A., \& Sari, A. (2020a). Are eco-innovation and export diversification mutually exclusive to control. Journal of Environmental Management, 270, 1-8.

Wang, L., Vo, X. V., Shahbaz, M., \& Ak, A. (2020b). Globalization and carbon emissions: Is there any role of agriculture value-added, financial development, and natural resource rent in the aftermath of COP 21 ? Journal of Environmental Management, 268, 1-8.

Wang, R., Mirza, N., Vasbieva, D. G., Abbas, Q., \& Xiong, D. (2020c). The nexus of carbon emissions, financial development, renewable energy consumption, and technological innovation: What should be the priorities in light of COP 21 Agreements? Journal of Environmental Management, 271, 1-7.

World Development Indicators (WDI). (2018). World Bank: Washington, DC, USA. Retrieved on July 15, 2020 from https://databank.worldbank.org/source/worlddevelopment-indicators.

World Bank. (2007). International trade and climate change: Economic, legal, and institutional perspectives. World Bank. https://doi.org/10.1596/978-0-8213-7225-8

World Bank. (2020). Transport: The essential connector. World Bank Report. February, 2020. https://thedocs. worldbank.org/en/doc/157201585683713721-0190022020/original/WBTransportNarrative.pdf

WTO (World Trade Organization) (2017). WTO's Trade facilitation agreement enters into force. Retrieved on July 19, 2020 from www.wto.org/english/news_e/news17_e/fac_31jan17_e.htm.

WTO (World Trade Organization). (2021a). Chair summary following COVID-19 and vaccine equity: What can the WTO contribute. Speech by D. G. Okonjo. WTO, Geneva. Retrieved on August 12, 2021 from https://www.wto.org/english/news_e/spno_e/spno5_e.htm.

WTO (World Trade Organization). (2021b). Global trade rebound beats expectations but marked by regional divergences. WTO Press Release No. 889. Retrieved on October 12, 2021 from https://www.wto.org/ english/news_e/pres21_e/pr889_e.pdf

Wu, W., Zhang, M., \& Ding, Y. (2020). Exploring the effect of economic and environment factors on PM2.5 concentration: A case study of the Beijing-Tianjin-Hebei region. Journal of Environmental Management, $268,1-9$.

Xu, F., Huang, Q., Yue, H., He, C., Wang, C., \& Zhang, H. (2020). Reexamining the relationship between urbanization and pollutant emissions in China based on the STIRPAT model. Journal of Environmental Management, 273, 111134. https://doi.org/10.1016/j.jenvman.2020.111134

Yu, W., Chavez, R., \& Feng, M. (2017). Green supply management and performance: A resource-based view. Production Planning \& Control, 28(6-8), 659-670.

Yunfeng, Y., \& Laike, Y. (2010). China's foreign trade and climate change: A case study of $\mathrm{CO}_{2}$ emissions. Energy Policy, 38(1), 350-356. https://doi.org/10.1016/j.enpol.2009.09.025 
Zafar, M. W., Qin, Q., Malik, M. N., \& Zaidi, S. A. H. (2020). Foreign direct investment and education as determinants of environmental quality: The importance of post Paris Agreement (COP21). Journal of Environmental Management, 270, 110827. https://doi.org/10.1016/j.jenvman.2020.110827

Zhang, K., Shao, S., \& Fan, S. (2020). Market integration and environmental quality: Evidence from the Yangtze river delta region of China. Journal of Environmental Management, 261, 110208. https://doi. org/10.1016/j.jenvman.2020.110208

Publisher's Note Springer Nature remains neutral with regard to jurisdictional claims in published maps and institutional affiliations. 